\title{
The Radiative Forcing of Aerosol-Cloud Interactions in Liquid Clouds: Wrestling and Embracing Uncertainty
}

\author{
Johannes Mülmenstädt ${ }^{1}$ (D) . Graham Feingold ${ }^{2}$ (1) \\ Published online: 17 February 2018 \\ (C) The Author(s) 2018. This article is an open access publication
}

\begin{abstract}
This article discusses some of the challenges that have limited progress in quantifying the radiative forcing associated with aerosol-cloud interactions (ACI) in warm (liquid-water) clouds. It reviews recent progress and suggests new ways of viewing the problem that might accelerate progress. It calls for much greater attention to the scale problem, both in terms of aerosol-cloud process representation in models and comparison with observations. It suggests careful consideration of the balance in detail with which processes are represented, and proposes a merging of detailed process understanding and system-wide behavior. In this spirit, it advocates tackling the problem with models of varying complexity that consider both the depth and breadth of the complex dynamical system. Finally, it considers shifting attention from untangling aerosol and meteorological effects on cloud systems towards understanding the co-variability of key aerosol and meteorological drivers of cloud systems.
\end{abstract}

Keywords Aerosol-cloud interactions - Aerosol radiative forcing · Liquid water clouds - Complex systems · Observational constraints

\section{Introduction}

Climate forcing associated with the atmospheric aerosol has been singled out by Intergovernmental Panel on Climate Change (IPCC) assessments as contributing the largest uncertainty to total radiative forcing estimates (e.g., [18]). Particularly stubborn is the problem of aerosol effects on the amount and brightness of warm, shallow clouds that cover large areas of the oceans and provide a cooling effect that partially offsets the warming associated with greenhouse gases. Our uncertainty in the radiative forcing associated with aerosol-cloud interactions ("indirect effects") is further exacerbated by our uncertainty in how these warm clouds

This article is part of the Topical Collection on Aerosols and Climate

Johannes Mülmenstädt

johannes.muelmenstaedt@uni-leipzig.de

1 Institute of Meteorology, Universität Leipzig, Leipzig, Germany

2 Chemical Sciences Division, NOAA Earth System Research Laboratory, Boulder, CO, USA will respond to a warming climate (the "cloud feedback" problem) and how they relate to climate sensitivity.

In spite of abundant evidence of aerosol influences on the amount and radiative properties of shallow liquid water clouds, the quantification of these effects has proven elusive. The goal of this paper is to outline reasons why the task is so difficult, and to review recent progress in the understanding of aerosol-cloud interactions and quantification of their radiative forcing. We will organize our discussion around estimates of the climate forcing of the anthropogenic aerosol, conventionally expressed as an effective radiative forcing (ERF) relative to the preindustrial climate state. We will restrict our discussion to aerosolcloud interactions in warm (liquid-phase) clouds, given their tight connection to other unresolved climate change questions such as cloud feedbacks and climate sensitivity; we refer the reader to [78] for a comprehensive discussion of mixed- and ice-phase aerosol-cloud interactions (ACI). We will not cover questions associated with the abundance, size distribution, composition, and anthropogenic fraction of the atmospheric aerosol, since many other excellent papers have already done so (e.g., [106, 108]). We will also not deal with forcing associated with aerosol-radiation interactions that act on large spatiotemporal scales by changing regional circulation patterns (e.g., [17, 115, 133]). In addition to 
reviewing progress, we will discuss fundamental challenges inherent to quantification of $\mathrm{ERF}_{\mathrm{aci}}$ and suggest new conceptual ways of thinking about aerosol-cloud-climate forcing. Our hope is that these might facilitate progress towards reducing, or at the very least understanding, sources of uncertainty so that modeling and observational programs can be designed accordingly.

\section{State of the Field}

We begin our review of the current state of the field with a summary of why the ACI problem is so persistent in the face of currently available methods of estimating $\mathrm{ERF}_{\mathrm{aci}}$, what those methods are, and what progress has been made since the Fifth IPCC assessment (AR5).

\section{Why Are ERF aci Estimates so Challenging?}

A Problem of Scales Like dragons of yore, the ERF $F_{\text {aci }}$ problem uses scales to resist its attackers. The first scale is energetic: the $\mathrm{ERF}_{\mathrm{aci}}$ is approximately two orders of magnitude smaller than the shortwave cloud radiative effect (e.g., [153]). The path to a $1 \%$ effect goes partly through large perturbations that occur rarely, or over limited areas (shiptracks, closing of open cells; [47]), and small perturbations that occur frequently, posing challenges for observability. For example, [122] indicate that shiptracks, the most eminently observable manifestation of ACI, exert a paltry $0.5 \mathrm{~mW} \mathrm{~m}^{-2}$ of forcing globally. The challenge is therefore to determine the meteorological conditions under which aerosol perturbations manifest as energetically significant, along with their geographical coverage and frequency of occurrence.

The second set of scales is spatiotemporal: the scales relevant for ACI range from the microscale through cloudprocess scales for cloud-top turbulent entrainment and cloud updrafts. However, the aerosol perturbations at cloud-scale affect the regional and global circulation, and these regional- through global scale changes feed back as meteorological influences on cloud processes [112, 133, $150,151]$. This means that constraining $E_{R F}$ aci requires understanding the microscale, the cloud process scale, and the global scale, as well as the interactions between scales.

Tools General circulation models (GCMs), our primary tools for quantifying the radiative forcing associated with aerosol-cloud interactions, are particularly ill-suited to resolve the level of detail of aerosol and cloud processes that matters for quantification of forcing. Process models that focus on the details of aerosol-cloud interactions at fine scales (order 10s of meters) have proven very useful for elucidating the underlying physical processes within the highly coupled system, but they lack the ability to incorporate the large range of spatiotemporal scales that are required to assess these effects regionally and globally. The community thus navigates between the Greek mythological sea monsters of Scylla and Charybdis, maneuvering between quantification based on models that incorporate the appropriate spatiotemporal scales but lack the necessary process-level details, and models that resolve the details but are unable to provide quantification at climate-relevant spatiotemporal scales.

Data from airborne, space-based, and ground-based platforms are key to improving models of all scales. Observing systems have progressed significantly in recent decades, yielding copious amounts of the data that are crucial to advancing our understanding. Observations are not without problems; here too the question of measurement scale rears its head. In situ measurements, while providing great detail, typically represent very small volumes of the atmosphere. Ground-based remote sensing, using instrument arrays that simultaneously measure cloud and aerosol properties, provide long-term records of larger volumes, but with the drawback of uncertainties inherent to remote sensing (e.g., [31]). At larger scales, satellite-based observing systems provide global coverage of key aerosol and cloud properties, but at reduced spatial resolution and with the added complication that it is difficult to retrieve aerosol and cloud properties simultaneously in the same column (e.g., [28, 62]).

Inferring Forcing from Present-Day Conditions A significant challenge to evaluating $\mathrm{ERF}_{\mathrm{aci}}$ is that, by definition, $\mathrm{ERF}_{\text {aci }}$ addresses the present-day (PD) forcing relative to a preindustrial (PI) base state. Our lack of observations and lack of knowledge of the PI aerosol leaves much uncertainty (e.g., [24]). For example, assumptions about PI drop concentration $N_{d}$ or aerosol concentration $N_{a}$ strongly contribute to uncertainty in forcing estimates [23, 57]. Recent and planned field experiments are focusing on the remote clean marine environment in search for proxies for PI conditions (e.g., [92]).

Penner et al. [105] and Ghan et al. [42] have explained the difference between satellite-based and GCM estimates of $\mathrm{ERF}_{\mathrm{aci}}$ as resulting from the satellite-based analyses' use of PD variability as a proxy for the PD minus PI change in aerosol, which they claim results in a significant low bias in ACI metrics. As shown by [52], this bias can be mitigated by using the aerosol index (the product of aerosol optical depth and the Angström exponent), which is a better proxy for anthropogenic $N_{a}$ than the particularly problematic aerosol optical depth (AOD); satellite-model $\mathrm{ERF}_{\mathrm{aci}}$ differences can be further reduced by avoiding numerical issues related to the small changes in $N_{d}$ in relatively pristine areas. 
Equifinality The climate system (or parts thereof) is an open system and therefore characterized by "equifinality", i.e., similar outcomes may be achieved with different representations of model processes [12].

It has been demonstrated that models with equally plausible but different process representations can match observations of the global-mean temperature record, or in the case of fine-scale models, observations of basic cloud field properties (e.g., [13]). The question that follows is whether equifinality could present an obstacle to our ability to constrain the system through observations of the atmospheric state and processes. And, in the face of equifinality, how can we determine which models will have the most predictive power? This theme will be discussed further in "Improving Observational Constraints on GCMs" and "Blending Modeling Approaches".

Abstraction of Physical Processes To represent ACI in GCMs, a specific parameterization has to be implemented for each indirect effect (specifically for warm clouds, an aerosol activation scheme for the "first indirect effect", an $N_{d}$-dependent precipitation scheme for the "second indirect effect"); as the tools available shape the science and analysis, this association between parameterizations and aerosol effects has shaped the thinking about ACI in GCMs, leading to the " $n$-th indirect effect" paradigm often criticized by the process-scale community. The first indirect effect (or albedo effect) is conceptually well defined, and observationally based, although not straightforward to quantify in GCMs because of their lack of resolution of updrafts (e.g., [152]); the second indirect effect (or lifetime effect), however, encompasses numerous hypotheses, none of which is directly linked to cloud lifecycles, nor wellrooted in observations [138]. It is largely a GCM construct that removes condensate from the atmosphere based on the the degree to which "autoconversion" of cloud water to rain water is sensitive to the aerosol. Real clouds experience subtle responses to aerosol perturbations as a result of adjustments, at a range of scales, of the cloud system to the aerosol, and to its constantly adjusting environment. In some cases, internal adjustments within the system absorb or "buffer" the system to aerosol perturbations, typically by reducing the cloud amount (e.g., [19, 138]). In other cases, the system is very sensitive to the aerosol, e.g., in stratocumulus clouds where the absence or presence of aerosol can determine whether the cloud field takes on an open or closed cellular structure (e.g., [130]).

The aforementioned adjustments occur at scales of hours, and are difficult to observe because of a fundamental problem of attributing the change in cloud amount to an external agent in a system that adjusts to its environment, and at the same time modifies its environment. The typical approach to quantifying the lifetime effect is via observations of the response of cloud liquid water path $(\mathscr{L})$ to a change in $N_{a}\left(d \mathscr{L} / d N_{a}\right)$ based on regression of highly aggregated data (e.g., [26]). Whether this approach adequately reflects the true responses, averaged up to the observational scale, is unknown.

A consequence of categorizing indirect effects into the albedo and lifetime effects is that the community often focuses on processes that are amenable to parameterization at the expense of others. For example, cloud-scale mixing with the environment receives little attention, in part because it is difficult to parameterize in GCMs (e.g., [95, $114,162])$, and yet the details of how mixing is represented could be 2-3 times more important with respect to cloud brightening than is the aerosol brightening of clouds [59].

Inferring Process from Snapshots Observations of the aerosol-cloud system, be they in-situ, satellite-, or groundbased, undoubtedly provide important constraints on the realism of model simulations and, with well-quantified measurement errors, a means to improve models. But a somewhat neglected aspect of the model-observation comparison is that observations provide snapshots of the system at various stages of its evolution. From these fragmentary (in time) pieces of information, bolstered by very large statistics that permit binning in what we believe to be the cloud-controlling variables, we attempt to infer process understanding of the evolving aerosol-shallow cloud system. Studies have used revisits of a scene by the same or different satellites (e.g., [49, 50, 86, 93]), but the revisit intervals are coarse compared to cloud-adjustment timescales. [118] have used a combination of polar-orbiting and geostationary satellites, but for many aerosol-cloud studies, geostationary satellites have had insufficient spatial and spectral resolution until recently.

Thus, an essentially temporally evolving system with an inherent memory is studied with a Markovian, "snapshotin-time" methodology, which assumes that processes are related to the current state of the system, and have no memory of past states. Observations have been demonstrated to be useful for inferring knowledge of aerosol-cloud microphysical processes (e.g., [76, 77, 83, 100, 134-136]). An important question is whether the non-Markovian nature of the system presents some fundamental limitation to the extent to which one can develop a deeper understanding and quantification of aerosol-cloud processes with snapshots. While this is not the topic of the current paper, we advocate delving deeper into this issue and adapting our measurement approaches so that we not only constrain models, but also maximize our understanding of physical processes. New geostationary satellites such as Himawari and GOES-16, with their multi-spectral capabilities and much improved spatiotemporal resolution, will surely be illuminating. 


\section{Current ERF aci Estimates}

Broadly, the tools available for studying ACI are in situ observations, space- and ground-based remote sensing, and a range of models spanning fine-scale models to GCMs. Seinfeld et al. [128] provide a thorough summary of the specific strengths as well as shortcomings of each tool at particular spatiotemporal scales. One of the promising developments in the recent past has been the increasing use of combinations of tools to mitigate these shortcomings and maximize strengths in $\mathrm{ERF}_{\mathrm{aci}}$ estimates. Promising progress has also been made towards understanding the systematic discrepancy between GCM-based and observationally based $E F_{a c i}$ estimates and on more rigorously understanding the sensitivity of GCM ERF $\mathrm{Fci}_{\mathrm{a}}$ to modeling assumptions. In this section, we summarize studies from these promising categories. We do not attempt to be exhaustive in summarizing GCM-based estimates; [78] and [79] provide an excellent compilation of such studies since AR5.

Combinations of multiple tools can take the form of constraining model behavior to observations (e.g., [52, 110, 148]) or of using a combination of observations and reanalysis to address the problem of concurrently observing aerosol and cloud from satellite (e.g., [26, 90, 91]). (We discuss [110] and [148] in greater detail in the context of emergent constraints; see "Improving Observational Constraints on GCMs"). Chen et al. [26] and McCoy et al. [90, 91] have used aerosol fields from chemical transport models to avoid the problems of collocated aerosol and cloud retrievals. Chen et al. [26] separate their forcing estimate into an "extrinsic" (due to adjustments in cloud fraction) $\mathrm{ERF}_{\text {aci }}$ contribution of $-0.46 \pm 0.31 \mathrm{~W} \mathrm{~m}^{-2}$ and an "intrinsic" (due to changes in $N_{d}$ and $\mathscr{L}$ ) $\mathrm{ERF}_{\text {aci }}$ contribution of $-0.49 \pm 0.33 \mathrm{~W} \mathrm{~m}^{-2}$; $[90,91]$ report an $\mathrm{RF}_{\text {aci }}$ (i.e., the forcing due to $N_{d}$ change only) of $-0.97 \mathrm{~W} \mathrm{~m}^{-2}$.

The above-cited studies only partially address the difficult problems of causality and meteorological confounding by small-scale variations in humidity that are correlated with both cloudiness and AOD [28, 62, 109]. Gryspeerdt et al. [51] take a significant step forward by using $N_{d}$ as an intermediary variable to reduce the meteorological component of a causal relationship between aerosol and cloud fraction. Their estimate of the contribution to $\mathrm{ERF}_{\text {aci }}$ due to the cloud fraction response of liquid clouds is $-0.48(-0.1$ to -0.64$) \mathrm{W} \mathrm{m}^{-2}$.

As discussed in "Why Are ERF $\mathrm{Eci}_{\mathrm{aci}}$ Estimates so Challenging?", progress is being made on understanding the discrepancy between GCM and observational estimates of $\mathrm{ERF}_{\mathrm{aci}}$, which was large in $\mathrm{AR5}\left(\mathrm{ERF}_{\mathrm{ari}+\mathrm{aci}}=-0.93\right.$ to $-0.45 \mathrm{~W} \mathrm{~m}^{-2}$ with a median of $-0.85 \mathrm{~W} \mathrm{~m}^{-2}$ for studies using the satellite record, compared against -1.68 to $-0.81 \mathrm{~W} \mathrm{~m}^{-2}$ with a median value of $-1.38 \mathrm{~W} \mathrm{~m}^{-2}$ for GCM studies; [18]). Gryspeerdt et al. [52] show that the choice of $N_{a}$ proxy can significantly reduce the discrepancy; their best estimate of $\mathrm{RF}_{\text {aci }}$ based on a GCMobservation combination is $-0.4 \mathrm{~W} \mathrm{~m}^{-2}$. Christensen et al. [28] and Neubauer et al. [102] take a different approach, investigating the effects of reducing near-cloud biases in satellite aerosol observations consistently between observations and modeling. This simplification of ACI, where the effect of clouds on aerosols is reduced, succeeds at bringing the GCM and observations into agreement and leads to a reduction in the intrinsic $\mathrm{ERF}_{\mathrm{aci}}$ to $-0.28 \pm 0.26 \mathrm{~W} \mathrm{~m}^{-2}$ from $-0.49 \pm 0.18 \mathrm{~W} \mathrm{~m}^{-2}$ when no removal of near-cloud aerosol observations is performed. However, the distant aerosol field can also be expected to have less causal connection with the aerosol that perturbed the cloud; the resulting forcing estimate should probably be considered an upper (i.e., least negative) bound.

Considering the difficulties arising in the interpretation of multimodel intercomparisons (see "On the Suitability of $\mathrm{ERF}_{\mathrm{aci}}$ as a Global Synopsis of ACI"), we believe modeling studies that carefully analyze the sensitivity of model projections to assumptions underlying the parameterized processes to be useful. Notable studies of this type have characterized the GCM ERF aci sensitivity to parameterized precipitation $[40,116]$, turbulence $[38,101]$, and aerosol processing by cloud [101, 102]. The value of such studies is to point out the sources of uncertainty in model projections, perhaps leading towards tighter constraints; we discuss this possibility in greater detail in "Improving Observational Constraints on GCMs". Nevertheless, results from such exercises should not be overinterpreted, since, if the models do not resolve important aerosol and cloud processes adequately, they likely do not reflect the correct susceptibility to aerosol perturbations. [101] and [82] have investigated the effect of increasing model resolution on ACI; [82] do not provide $\mathrm{ERF}_{\text {aci }}$ estimates, but do indicate that higher model resolutions favor a stronger droplet-number response and a weaker precipitation response, in line with process-scale evidence (see "Improving Observational Constraints on GCMs") and our sentiment that susceptibilities will be incorrect if processes are not resolved adequately. Confidence in these sensitivity studies may be enhanced through the increased use of subgrid-scale representation and unified convection/ turbulence/ cloud schemes [40].

The range of reported $\mathrm{ERF}_{\mathrm{aci}}$ estimates remains large, as does the uncertainty in those studies that provide an uncertainty estimate. Different methodologies are used for estimating $\mathrm{ERF}_{\mathrm{aci}}$, all of which have known deficiencies; definitions of uncertainty abound (statistical versus systematic, with different systematic effects considered by each study, and different methods used to estimate each systematic effect). This makes it highly nontrivial to synthesize the various results into a combined $\mathrm{ERF}_{\mathrm{aci}}$ 
estimate. In AR5, the final estimate of $\mathrm{ERF}_{\mathrm{aci}}$ was based on subjective expert judgment. We advocate against this subjective method, which obscures the assumptions and hypotheses that enter the estimate, making them hard to falsify (e.g., [55]). For future assessments, we hope that a more formal, traceable approach such as the Bayesian formalism in [139] will be adopted (see "Hypothesis Refutation").

\section{On the Suitability of ERF aci as a Global Synopsis of $\mathrm{ACl}$}

Tight constraints on aerosol $\mathrm{ERF}_{\mathrm{aci}}$ are desirable primarily for two reasons: first, to aid estimates of climate sensitivity from the historical record; and second, to provide insights into a future where aerosol emissions will be drastically reduced. These two "customers" of the ERF aci "product" have slightly different requirements, so it is worthwhile thinking carefully about whether a single scalar $\mathrm{ERF}_{\mathrm{aci}}$ relative to PI aerosol, which is so often taken as the holy grail of the aerosol-cloud community, is in fact the most suitable output to provide.

Because of the historical entanglement of aerosol and greenhouse gas forcing, estimating the climate sensitivity from the observational record requires knowledge of the historical aerosol forcing (e.g., [4, 64]). To quantify the uncertainty in climate sensitivity resulting from a given aerosol forcing estimate requires knowledge not only of the forcing but also of its uncertainty. This raises the question of what specific form the $\mathrm{ERF}_{\mathrm{aci}}$ uncertainty estimate should take: do confidence intervals suffice, or do we need to constrain the shape of the $\mathrm{ERF}_{\mathrm{aci}}$ probability density function (PDF) as well? In light of the importance of the uncertainty estimate, we also need to think carefully about the methods by which it is derived. One source is GCM intermodel spread (e.g., [36, 42, 52, 145, 161]), but this source is plagued by problems of errors versus uncertainty, representativeness of the model diversity [66], and common lineages of model components ([6], and references therein); further, model spread may be biased by requiring the model $E F_{a c i}$ to lie within the consensus range [119]. Attempts to set bounds with more rigorous methods are discussed in "Hypothesis Refutation". A second way in which forcing and feedbacks are entangled is through aerosol feedbacks, where a warmer climate system produces higher natural aerosol emissions and thus potentially increased aerosol radiative forcing [41, 72] or where the faster hydrological cycle in a warmer climate leads to increased aerosol scavenging and thus potentially decreased aerosol radiative forcing (e.g., [97]).

The PD aerosol forcing relative to PI is often used for insights into the aerosol forcing in a clean-air, but not necessarily a decarbonized, future. These insights are imperfect for two reasons. Even with stringent emissions controls, the anthropogenic fraction of total aerosol may still be large compared to preindustrial conditions [8]. Furthermore, in the future climate, the perturbations to cloud induced by greenhouse gas forcing and global warming will be even larger than in the present, and so (in the language of [38]) will the importance of the "C" relative to "A" in ACI. As pointed out by [98] and [79], ACI modulate cloud fields that are also affected by greenhouse gas-warming-induced changes; these changes will become increasingly large in the future climate and are neglected in the current method of diagnosing aerosol forcing in GCMs.

Thus, we should keep in mind the intended use of the aerosol forcing estimate and that the aerosol forcing problem and the feedback problem cannot be neatly compartmentalized.

\section{Reducing the $E_{\text {Raci }}$ Uncertainty}

In light of the continuing large uncertainty on $\mathrm{ERF}_{\mathrm{aci}}$, we now discuss specific (and published) ideas that we believe have the potential to reduce that uncertainty. We then offer a conceptual framework that might assist in achieving this goal.

\section{The Scale Gap in GCMs}

Recognizing that $\mathrm{ERF}_{\mathrm{aci}}$ is determined on scales from the cloud-process scale to the general-circulation scale is essential to grasping the magnitude of the ACI problem. Conceptually, the simplest method would be to increase GCM resolution sufficiently to represent cloud-process scales $\sim \mathscr{O}(10 \mathrm{~m})$; assuming exponential increases in computing power continue at the current rate, computational capability will have caught up with this resolution in half a century, when aerosol forcing may well be irrelevant and climate sensitivity can be determined from direct temperature measurements [96, 121]. Furthermore, it is likely that, even then, uncertainty due to parameterized microphysics will continue to be an issue, much like in fine-scale models currently.

In the interim, GCMs more frequently include subgridscale representations of clouds using Eddy Diffusivity/ Mass Flux [131] or high-order closure schemes [15, 74] that have demonstrated success in improving shallow convection. When coupled with microphysical models, they have the potential to provide better representation of ACI. In addition, the multiscale modeling framework (an embedded cloud resolving model within a GCM grid box) [48, 104, $111,117]$ provides a way forward. Vertical resolution is a persistent problem for shallow clouds, particularly stratocumulus, and new ideas have been proposed to 
locally apply an adaptive vertical mesh [85, 159] when stratocumulus conditions are expected.

A central question is what resolution is required to capture the climatically relevant aspects of aerosol-cloud interactions. At what scale do we need to resolve clouds and aerosol-cloud interactions to quantify $\mathrm{ERF}_{\text {aci }}$ ? How important is resolution for quantifying closely related aspects such as cloud feedbacks? The answers may only emerge through concentrated efforts to improve the representation of clouds and aerosol-cloud interactions in GCMs.

\section{Ensuring Scale Awareness in Model-Observation Intercomparisons}

Scale has consequences for model-observation comparisons. Too frequently, little attention is paid to this issue, rendering comparisons of questionable value. An exercise simulating comparison between perfect model output (200$\mathrm{km}$ scale) and perfect observations (10-km scale) shows biases of between 30 and $160 \%$ due entirely to different spatial sampling of models and observations; such errors are often larger than measurement errors in real observations [124]. Similarly large biases can occur when care is not taken to ensure temporal synchronicity in data [125]. Furthermore, a lack of consideration of the diurnally biased sampling associated with polar-orbiting satellites can bias results significantly $[93,123]$. The spatial heterogeneity of observations also needs careful consideration. Data is often discontinuous in space and time, requiring geospatial statistical methods to address data heterogeneity when comparing to regularly gridded model output [123].

Scale also influences the calculation of susceptibilities, whether they are calculated based on observations or model output. Harmonizing the analysis scales between observations and modeling, while recognizing the relevant process scales, is important if one is to conduct meaningful comparisons of ACI metrics (susceptibilities) [89].

The unequivocal conclusion of these studies is that observational studies, and attempts to constrain models observationally, must pay careful attention to scale for their conclusions to be of value.

\section{Improving Observational Constraints on GCMs}

An aspect of equifinality that GCMs must contend with is that the model parameters that most strongly control the PD state of a model are not always the ones that determine its sensitivity to anthropogenic greenhouse gas or aerosol forcing: the PD state tends to be controlled by overall process rate scale factors, whereas sensitivity to forcing tends to be controlled, inter alia, by preindustrial aerosol properties and process rate sensitivities to aerosol
$[23,57,80]$. In our opinion, it is an open question whether this implies a fundamental limitation on the ability of PD observational constraints to constrain climate projections. Our hope is that a more suitable choice of observations that constrain model $\mathrm{ERF}_{\mathrm{aci}}$ can be identified, presumably ones that constrain the sensitivity of models to PD variability in aerosol. This section offers suggestions of what such observational constraints might be.

Emergent Constraints One potential way forward is using "emergent constraints" (ECs), which relate an unobservable sensitivity of the climate system to a modeled state of the system that is also observable. The idea is that if a physically understandable and robust relationship exists between sensitivity and system state in the model world, then observations of the system state can be used to quantify the sensitivity. The first EC to be considered for $E F_{a c i}$ [110] looked at cloud macroscale property responses to aerosol perturbations, and their relationship to $\mathrm{ERF}_{\text {aci }}$. Another proposed EC relates the susceptibility of probability of precipitation $\left(S_{\text {pop }}\right)$ to $\mathrm{ERF}_{\text {aci }}$ [148]. [65] have formulated a set of guidelines for identifying robust ECs: strong physical basis, robustness to choice of model ensemble, no obvious multiple influences, and reasonably high correlation between predictor and predictand. Whether the ECs of [148] and [110] meet these criteria is the subject of debate $[42,75]$ : the ECs are not based on well-resolved clouds and so their applicability may be questionable; in addition, the ECs are predicated on the "lifetime effect", which in GCMs presupposes an increase in cloud lifetime with increasing aerosol. The debate highlights that effort to address the shortcomings of the $S_{\text {pop-based EC is well }}$ spent and that the inadequate treatment of subgrid-scale clouds and precipitation in GCMs requires urgent attention. Thus, a partial answer to the question posed in "The Scale Gap in GCMs", "what resolution is required to capture the climatically relevant aspects of aerosol-cloud interactions?" might lie in the robustness of an EC to an increase in model and process resolution.

Process-Based Observational Constraints GCM estimates of ACI adjustments are highly sensitive to the parameterization of warm-rain collection processes (e.g., [38, 94, 107]); these detailed drop-drop interaction processes are lumped into "autoconversion", representing the collision of cloud droplets to form rain, and "accretion", representing the collection of cloud droplets by rain embryos. Autoconversion schemes use power-law fits in liquid-water mixing ratio and $N_{d}$ to observational or process-scale modeling datasets [63, 155], with "enhancement" corrections applied to account for the discrepancy between the available GCM gridbox mean mixing ratio and the high-liquid part of the subgrid variability that drives warm rain in reality; at the same time, 
the autoconversion scheme, in its capacity as a sink for low cloud, is a popular mechanism for tuning the TOA shortwave flux [45, 58, 80, 88, 119].

In addition to the autoconversion scheme, the precipitation production partitioning between autoconversion and accretion also strongly affects ACI adjustments [40, 94, 116]. Conventional precipitation observations (total precipitation amounts) are not sensitive to this partitioning; more process-oriented observations are needed to constrain the $E F_{\text {aci }}$ sensitivity to precipitation parameterizations. Due to its ability to resolve the vertical structure of precipitating clouds and its ability to detect drizzle, CloudSat is particularly suitable for providing such observational constraints, for example through the "Contoured Frequency of Optical Depth Diagram" (CFODD) method [141-143].

Observational Record as Constraint Using the observational record of global-mean surface temperature over the 20th century as a constraint on aerosol radiative forcing has been attempted in many ways but is fraught with problems. The most immediate problem is that the observational record is a superposition of internal variability, greenhouse gas ERF, and aerosol ERF (e.g., [4, 64, 126]), and hence a constraint on each component individually cannot be extracted from the observational record of a single variable. More advanced methods attempt to use episodes of faster or slower warming in the historical record to derive multiple constraints from a single variable (e.g., [137]), noting the hemispheric asymmetry in aerosol forcing and the logarithmic increase in ACI with aerosol concentration. Examination of the zero-dimensional ACI model underlying the [137] $\mathrm{ERF}_{\text {aci }}$ limits shows that GCMs predict a much more linear relationship between global-mean $\mathrm{ERF}_{\mathrm{aci}}$ and global-mean aerosol emissions [73, 113] due to the fact that the PD climate system still contains large regions where the $\mathrm{ACI}$ is far from saturated. With a linear relationship, the [137] constraint weakens to $\mathrm{ERF}_{\text {ari+aci }}>-1.6 \mathrm{~W} \mathrm{~m}^{-2}$, which is not a meaningful narrowing of the consensus range. This point is also illustrated by the experience that models with a historical aerosol forcing sufficiently strong to produce a counterfactual cooling during the second half of the 20th century lie far outside the accepted range of $\mathrm{ERF}_{\text {aci }}$ [46], again providing no more stringent a constraint than $\mathrm{ERF}_{\text {ari+aci }}>-1.6 \mathrm{~W} \mathrm{~m}^{-2}$.

\section{Translating Insights from Process-Scale Studies into Constraints on Global RRF $_{\text {aci }}$}

We address the problem of attempting to parameterize subgrid-scale cloud processes based on the information available at the GCM grid scale, as has been pursued by the cloud feedback community [20]. To enable such an approach, it would first be necessary to establish a community consensus on "robust" aerosol effects based on observations and process-scale modeling, as well as the GCM-scale conditions under which they apply. We propose the following list of cloud responses to increases in aerosol amount that, based on a synthesis of observations and fine-scale modeling, exhibit some robustness:

1. Increases in aerosol result in brighter clouds, ceteris paribus [144]. Questions still remain regarding the degree of brightening, which is influenced by aerosol size and composition.

2. Under clean conditions, cloud amount increases in response to increasing aerosol; this includes deepening of clouds and an increase in cloud fraction [3, 27, 30, $54,68,127,160]$. The aerosol helps stabilize a system likely to precipitate (a colloidally unstable system). The corollary is that systems increasingly approaching colloidal instability tend to move rapidly towards a low cloudiness state $[7,35]$.

3. Counteracting effects often create a buffered system; evaporation-entrainment-sedimentation feedbacks offset the deepening and increased cloud amount. This typically occurs in more polluted conditions [2, 21, 56, 149, 158]. Analysis of very large data sets sometimes shows no clear aerosol signal in the cloud radiative effect [129], and even massive aerosol perturbations from effusive volcanoes may not result in $\mathscr{L}$ and cloud fraction responses large enough to be detected above the meteorological noise over a few months [84].

4. Absorbing aerosol above cloud increases marine stratocumulus cloudiness [22, 60, 154]; absorbing aerosol in the boundary layer decreases cloudiness via reduction in surface fluxes over land and stabilization [1, 34, 70, 71, 132].

Rather than applying one-size-fits-all rules, it might be possible to translate the above responses into improved constraints on $\mathrm{ERF}_{\mathrm{aci}}$ by using the GCM-resolved fields to identify situations where we expect certain effects to dominate over opposing effects. For example, when aerosol concentrations are low and the boundary layer is deep (both conditions that GCMs might be trusted to diagnose reasonably well), process-scale modeling predicts large susceptibility of cloud fraction and liquid water path by precipitation suppression; conversely, in shallow, polluted boundary layers, process-scale modeling predicts negative susceptibilities due to enhanced cloud-top evaporation. We can envision different ways of feeding this process-scale knowledge back into the GCM; none is entirely satisfying, but at the very least, one could enforce a qualitatively correct GCM response to aerosol perturbations, increasing confidence in the model projections. 


\section{Untangling Versus Embracing Co-variability of Aerosol and Meteorology}

Because meteorology is a primary driver of cloudiness and small changes in meteorology can have a large influence, aerosol effects on the cloud system are difficult to separate from meteorological "noise". Typically, aerosol effects are examined within subsamples of data sorted by cloud controlling metrics such as lower tropospheric stability, or pressure vertical velocity at $500 \mathrm{hPa}$, which tends to sort the data by cloud regime (e.g., [76, 87]). While this is a useful approach, these metrics are imperfect, and small differences matter. An alternative might be to focus more effort on understanding the relationship between meteorology, aerosol, and cloudiness, i.e., to quantify the co-variability of meteorological variables among themselves and with the aerosol. The former would help limit the meteorological parameter space, defining distinct cloud regimes and, hence, reduce the number of degrees of freedom in the system. (This is the rationale behind metrics like lower tropospheric stability.) The latter would identify the conditions under which the aerosol is likely to have a more significant impact, opening the way to quantification of the frequency at which these conditions occur. Idealized cloud resolving models have in fact shown that the detectability of $\mathrm{ERF}_{\mathrm{aci}}$ depends on the co-variability of meteorological and aerosol conditions [32].

Routine modeling at observational sites that are well equipped with key cloud, aerosol, and radiation parameters are an attractive approach to improving model parameterizations (e.g., [99]). An added benefit is that they provide a wealth of data to quantify aerosol and meteorological covariability with both observations and observationally validated process model output. Proposed field experiments to evaluate solar radiation management [157], in conjunction with modeling, would provide valuable data to quantify the aerosol-cloud radiative effect in well-characterized settings.

How might one address susceptibility in this new framework? Practically speaking, a particular cloud type would be defined by key meteorological parameters. For the stratocumulus regime, this might consist of potential temperature $\theta$ and specific humidity $q_{t}$ profiles, their respective jumps at the boundary layer top $\left(\Delta \theta, \Delta q_{t}\right)$, and the boundary layer depth $H$. The typical observed range of stratocumulus $\mathscr{L}$, cloud base height, and cloud top height restricts the range of variability of the meteorological drivers that needs to be considered. Focusing then on the co-variability of aerosol and meteorological perturbations replaces the more traditional susceptibility (e.g., $d \mathscr{A} / d N_{a}$, where $\mathscr{A}$ is planetary albedo) by a broader definition $d \mathscr{A} / d X$ where $X \in\left\{\theta, q_{v}, \Delta \theta, \Delta q_{v}, H, N_{a}\right\}$. In other words, individual susceptibilities are replaced with the local slope of $\mathscr{A}$ (or other relevant cloud property) in six-dimensional parameter space that should be convolved with the co-variability of meteorological and aerosol properties.

As with uni-dimensional susceptibility metrics, one still has to admit the possibility that the co-variability of the $n$ parameters of interest changes with time. This topic would incorporate issues of (likely) positive cloud feedbacks and therefore a reduced cloud amount that could be perturbed by the aerosol through microphysical processes.

\section{Simple Models}

While the atmospheric science community has spent many decades developing models of ever-increasing complexity, complementary efforts have invested in alternative, and often much simpler, heuristic models, employing empiricism (e.g., [29]), network approaches [14, 44], simple computational frameworks $[39,156]$, or energy budget considerations ([25, 137], see below).

Pioneering efforts to consider simple dynamic system analogs to the complex atmospheric system date back to [81], who reduced the Navier-Stokes equations to three coupled differential equations and demonstrated the chaotic nature of weather systems. More recently, models comprising a few coupled differential equation models have been applied to microphysical processes [67, 146, 147], and to convection [16, 103], among others. These "simple" models are particularly useful since they have a small number of variables and free parameters, can be run many times, and are amenable to deeper understanding.

Increasingly, output from models of varying complexity is being analyzed in the dynamical systems language of stability and bifurcation [7, 9, 35, 69, 147], leading to a broader view of system susceptibility, e.g., the concept of "buffering" applied to aerosol-cloud interactions [138] can be interpreted as system stability (see below).

\section{Addressing Model Uncertainty}

In attempting to assess the importance of modeled processes, or the uncertainty in parameterizations, it is often standard practice to compare simulations that successively withhold individually selected processes. This approach has limited quantitative power because in coupled systems, it is the interaction between processes that determines model sensitivity. Statistical emulators, essentially sophisticated interpolators of an $n$-dimensional surface, allow a more robust assessment of the importance of individual processes $[23,61]$.

Another approach to assessing the uncertainty of model forecasts is through the use of stochastic representation of processes (e.g., [11]). The system is decomposed into slow (resolved and predictable) and fast (unresolved and 
unpredictable) scales, where only the statistical properties of the latter need to be represented. Berner et al. [11] argue that stochastic parameterizations "have the potential to trigger noise-induced regime transitions, and modify the response to changes in the external forcing," linking them closely to the concepts of system stability/bifurcation described above.

\section{Blending Modeling Approaches}

Two different philosophical approaches to studying complex systems have been proposed: the Darwinian approach has its roots in ecology and emphasizes system complexity. The complex system is broken down into individual components, each of which exhibits its own complexity. In the case of ACI this manifests as calculation of susceptibilities, which in aggregate, reflect the system wide behavior. In contrast, the Newtonian approach, which is rooted in physics, places emphasis on simplified equations, systemwide behavior, and emergent patterns. It breaks the system down into as small a number of parts as necessary for the problem at hand [53]. The benefits of merging these approaches has been discussed elsewhere [32, 53], and we reiterate that sentiment here. As an example of how these approaches differ, and how they might be merged, we consider how they apply to the calculation of $E_{\text {RF }}$. Figure 1 describes the methodology and conceptual approach in schematic form. The Darwinian approach breaks down aerosol influences on planetary albedo $\mathscr{A}$ into a long chain of expansions of derivatives (susceptibilities), each term requiring quantification if one is to constrain a model (e.g., [42]). ACI metrics that quantify cloud microphysical responses to changes in the aerosol are one such example (lowest panel in Fig. 1). The Newtonian system-wide view encourages simplified equation sets and meta-analyses that provide valuable context and constraints, e.g., the $\mathscr{A}$-cloud fraction relationship [10], or perhaps emergent behavior, or system attractors/bifurcation (upper panels in Fig. 1). Between the Darwinian ACI metrics and the Newtonian $\mathscr{A}$-cloud fraction analysis lies fertile ground for additional analyses. Examples include (1) the radar reflectivity $Z-$ cloud optical depth $\tau_{c}$ phase diagram [143], which sheds light on microphysical processes like the balance of condensation vs. collision-coalescence growth, (2) measurements that elucidate the radiative properties of a cloud field very directly such as the probability distribution function of up- or downward shortwave irradiance [120] or the cloud radiative forcing/effect- $\mathscr{L}$ phase diagram [129], and (3) cloud field properties such as cloud size distributions. Similar analyses of independent components/parameters would, when compounded, provide confidence in the predictive power of the model.

We refer back to "Equifinality", where we posed the question, "in the face of equifinality, how can we determine which models will have the most predictive power?" It would appear that analyses of as many orthogonal components of the system as possible, including higherorder statistics, would be the best path. The choice of components will depend on the model resolution and the fields of primary interest, but ideally, they would blend Newtonian and Darwinian approaches.

\section{Hypothesis Refutation}

Given the current inability of any given tool to represent the full spectrum of scales involved in determining the $\mathrm{ERF}_{\mathrm{aci}}$, estimates necessarily rely on a synthesis of evidence from different approaches. For the equilibrium climate sensitivity, [139] have proposed a method of "developing and refuting physical storylines (hypotheses) for values outside any proposed range". The specific recommendation here would be to make an argument for a certain upper bound on $\left|E R F_{a c i}\right|$ and then identify the conditions under which that upper bound is no longer justified. The advantage of this approach is that all lines of evidence can be taken into account in the $\mathrm{ERF}_{\text {aci }}$ bound, and that the contribution of each can be quantified via Bayesian inference [5]. Without this latter capability, it is difficult to falsify the assumptions and hypotheses that are implicit in the $\mathrm{ERF}_{\text {aci }}$ estimate through further research.

Simple models such as [137, 140], and [43] have a prominent place in this line of thinking, as the consequences of assumptions for $\mathrm{ERF}_{\mathrm{aci}}$ in these models are traceable and falsifiable. In an illustration of the falsifiability inherent in such models, the assumptions of [137] have been shown to be too simple to capture a key aspect of the physical system [73]; in an illustration of the traceability, reasonable parameter assumptions were shown by [43] to lead to an $\mathrm{ERF}_{\mathrm{aci}}$ spread far wider than the consensus range.

\section{Guiding Principles}

Persistent themes in this overview have been careful attention to scale, detail, and model complexity, all of which are linked. We conclude by outlining a number of guiding principles that we suggest be considered when embarking on model improvements and model-observation comparisons.

Attention to Scale Scale pervades this document in a variety of ways. As a start, we recall the tension between process resolution and climate-relevant spatiotemporal resolution, with no modeling system able to provide climate forecasts and at the same time adequately resolve small-scale processes relevant to $\mathrm{ERF}_{\mathrm{aci}}$. Increasing computational power might resolve this issue to some extent, as in the case 
Fig. 1 Schematic describing an integrated approach to constraining $\mathrm{ERF}_{\mathrm{aci}}$. The Newtonian view focuses on the aerosol-cloud systemwide behavior. The Darwinian approach focuses on details of elements of the aerosol-cloud system. A merging of Newtonian and Darwinian approaches can be achieved via a balance between metrics that constrain processes at various levels of detail: (i) traditional aerosolcloud interaction metrics (e.g., [33, 37, 42]); (ii) (joint) PDFs that illuminate physical processes [120, 143]; (iii) high-level analyses that address key ERF aci-relevant components [10, 129]; and (iv) emergent constraints [110, 148]. Analyses of all components can be derived from both observations and modeling. Comparisons should be done with appropriate attention to spatiotemporal scales. The right-hand side of the column conveys the emergence of a spiral-like motif embedded in a complex pattern

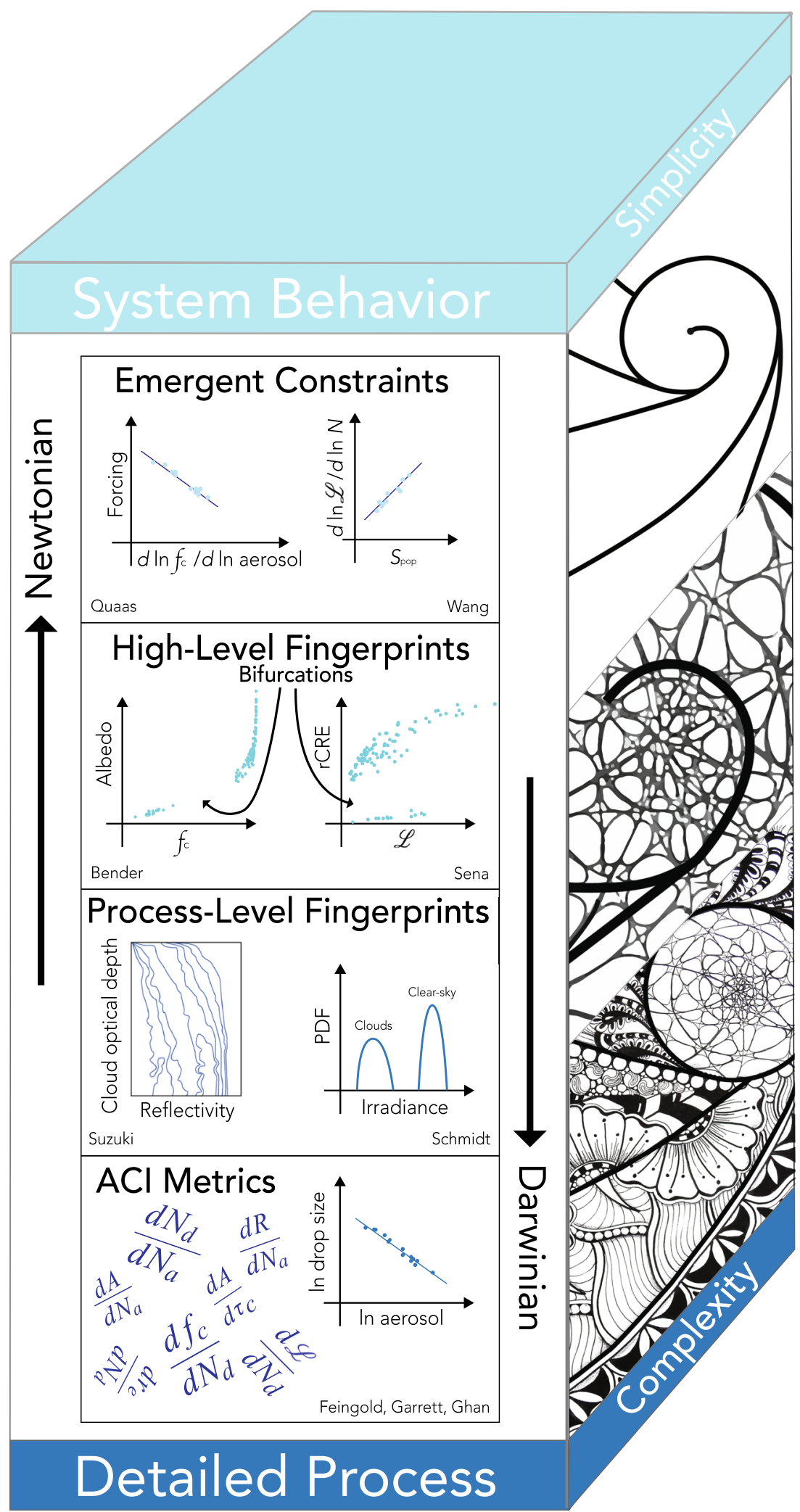

of global cloud resolving models that use the multimodeling framework, but these approaches are not a panacea, and regardless, we still foresee heavy competition for computational resources between earth system components and process representation within these components. In the latter case, there is a pervasive tension between the need for 
high spatial resolution to resolve small-scale motions and microphysical process resolution.

Scale emerges again when considering the mismatch between parameterizations that are often calculated based on theory or fine spatial scale models, and the coarse grid-mean model fields that drive them. This problem is of particular concern when processes are nonlinear with respect to climate model resolved fields (e.g., collisioncoalescence sensitivity to cloud water content).

In a similar vein, the use of observations for model evaluation deserves special attention to often neglected spatiotemporal aggregation scales to ensure that comparisons are meaningful.

Balance in Process Representation Computing advances have favored inclusion of increasingly detailed process representation into models that lack the infrastructure (resolution of cloud dynamics) to resolve said processes. Such detail is often inconsistently applied, with undue attention to representing processes for which parameterizations exist and insufficient (or perhaps appropriate, given our level of understanding, or GCM deficiencies) attention to other less accessible processes. Detailed cloud microphysics representation should be balanced with similar detail in other coupled components such as dynamics or radiation so that the system is well represented by its individual components. Advances in high-order closure representations of GCM subgrid processes provide such a balance for ACI studies.

Without this balance, there exists the danger that we will overinterpret model susceptibilities to well-studied processes and neglect other important but poorly represented processes. Moving away from traditional first and second indirect effects, and thinking more broadly about the coupled dynamical and microphysical interactions underlying $\mathrm{ERF}_{\mathrm{aci}}$, would seem worthy of pursuit. Finding new observational constraints will be equally challenging.

Balance in Darwinian vs. Newtonian Emphasis The multidisciplinary nature of the climate system would benefit from a thoughtful approach to balancing disciplinary detail with the broader multidisciplinary approach. "Reducing the ERF $F_{\text {aci }}$ Uncertainty" section and Fig. 1 outline the different philosophical approaches to studying complex systems: the Darwinian approach with its emphasis on detailed study of individual system components and the Newtonian approach with its emphasis on the systemwide behavior. We urge a balance in these approaches for maximum benefit. Processes should be presented with enough complexity to capture their essence, with careful consideration of the level of detail applied to other coupled components. An excessive focus on complexity can be detrimental to understanding of how the broader system works; and taking heed of emergence, patterns, stability, or bifurcations provides an important context for whether detail matters.

This approach does not detract from the desirability of detailed models to advance understanding of specific processes; nor does it suggest that GCMs be simplified excessively, or that we should not strive to raise the level of detail of coupled system components.

Models of Varying Complexity The rapid increase in computational power has driven model development towards complexity over simplicity to the degree that model output is increasingly difficult to interpret and causal relationships are nigh impossible to identify, let alone quantify. As with other complex systems that incorporate a very large number of coupled processes, the temptation is to compare simulations with and without a given process to assess the importance of said process. This approach is of little value because it is the combination of processes and their couplings that determines model sensitivity. Statistical emulators are proving useful for addressing this issue.

Models of a range of complexities, including dynamical system models and heuristic models, are sorely needed to filter forcing estimates derived from complex models. While such models are simple and imperfect representations of the complex system, they are accessible and can be easily tested to identify susceptibilities to various inputs. In conjunction with models of different levels of complexity, they provide additional lines of evidence that might lead to a consistent picture and help constrain $\mathrm{ERF}_{\mathrm{aci}}$.

\section{Untangling vs. Understanding Aerosol and Meteorological} Drivers Quantification of $\mathrm{ERF}_{\mathrm{aci}}$ has often been posed as a problem of untangling aerosol-driven from meteorologically driven changes in $\mathrm{ERF}_{\text {aci. }}$. Models, particularly those that resolve the relevant processes, allow one to change aerosol and meteorological inputs in idealized settings and are therefore useful for untangling these drivers. From the observational perspective, the problem is far more complex, given the sensitivity of the shallow cloud system to small changes in temperature and humidity profiles. The "untangling" is further complicated by the fact that the system is constantly adjusting to these drivers at a range of spatiotemporal scales, and yet, as noted above, observations typically comprise snapshots of an evolving system with revisit times much longer than some of the adjustment timescales.

An alternate approach is to shift the focus from untangling aerosol from meteorological drivers to understanding the co-variability of these drivers; identifying commonly occupied parameter space could reduce the dimensionality of the problem and could affect the strength and even detectability of $\mathrm{ERF}_{\mathrm{aci}}$. Routine large eddy modeling in conjunction with routine observations at supersites might prove 
particularly useful for assessing such co-variability and its impact on the aerosol-cloud radiative effect, particularly if such efforts are focused in key cloud regimes.

Acknowledgements We thank Ann Reiser for the original artwork and help with drafting the figure. We are grateful to Edward Gryspeerdt, Marc Salzmann, Tristan L'Ecuyer, Karoline Block, Tom Goren, and Johannes Quaas for stimulating discussion. Andrew Gettelman and an anonymous reviewer provided insightful comments that helped us clarify the manuscript. Open Access publication was funded by the "FLASH" project, project number QU 311/14-1, in the Priority Program SPP 1294 "HALO" funded by the German Research Foundation (Deutsche Forschungsgemeinschaft, DFG).

\section{Compliance with Ethical Standards}

Conflict of interest On behalf of all authors, the corresponding author states that there is no conflict of interest.

Open Access This article is distributed under the terms of the Creative Commons Attribution 4.0 International License (http:// creativecommons.org/licenses/by/4.0/), which permits unrestricted use, distribution, and reproduction in any medium, provided you give appropriate credit to the original author(s) and the source, provide a link to the Creative Commons license, and indicate if changes were made.

\section{References}

1. Ackerman A, Toon O, Stevens D, Heymsfield A, Ramanathan $\mathrm{V}$, Welton E. Reduction of tropical cloudiness by soot. Science. 2000;288(5468):1042-7. https://doi.org/10.1126/science.288.54 68.1042

2. Ackerman A, Kirkpatrick M, Stevens D, Toon O. The impact of humidity above stratiform clouds on indirect aerosol climate forcing. Nature. 2004;432(7020):1014-7. https://doi.org/10.103 8/nature03174.

3. Albrecht BA. Aerosols, cloud microphysics, and fractional cloudiness. Science. 1989;245(4923):1227-30.

4. Andreae MO, Jones CD, Cox PM. Strong present-day aerosol cooling implies a hot future. Nature. 2005;435(7046):1187-90. https://doi.org/10.1038/nature03671.

5. Annan JD. Recent developments in bayesian estimation of climate sensitivity. Current Climate Change Reports. 2015;1(4):263-7. https://doi.org/10.1007/s40641-015-0023-5.

6. Annan JD, Hargreaves JC. On the meaning of independence in climate science. Earth System Dynamics. 2017;8(1):211-24. https://doi.org/10.5194/esd-8-211-2017.

7. Baker M, Charlson R. Bistability of CCN concentrations and thermodynamics in the cloud-topped boundary-layer. Nature. 1990;345(6271):142-5. https://doi.org/10.1038/345142a0, A prescient study that exposed the role of the aerosol in the bistabilty of the boundary layer cloud system. Later confirmed through field measurements and modeling (e.g., [35]).

8. Bauer SE, Tsigaridis K, Miller R. Significant atmospheric aerosol pollution caused by world food cultivation. Geophys Res Lett. 2016;43(10):5394-400. https://doi.org/10.1002/2016GL0 68354.

9. Bellon G, Geoffroy O. Stratocumulus radiative effect, multiple equilibria of the well-mixed boundary layer and transition to shallow convection. Q J R Meteorol Soc. 2016;142(697, B):1685-96. https://doi.org/10.1002/qj.2762.
10. Bender FAM, Charlson RJ, Ekman AML, Leahy LV. Quantification of monthly mean regional-scale albedo of marine stratiform clouds in satellite observations and GCMs. J Appl Meteorol Climatol. 2011;50(10):2139-48. https://doi.org/10.1175/JAM C-D-11-049.1, A meta-analysis of scene albedo and cloud fraction - fields closely tied to $\mathrm{ERF}_{\text {aci }}$. The framework is useful as a diagnostic of GCM performance as well as a means to address detectability of $\mathrm{ERF}_{\text {aci }}$ [32].

11. Berner J, Achatz U, Batte L, Bengtsson L, de la Camara A, Christensen HM, Colangeli M, Coleman DRB, Crommelin D, Dolaptchiev SI, Franzke CLE, Friederichs P, Imkeller P, Jarvinen H, Juricke S, Kitsios V, Lott F, Lucarini V, Mahajan S, Palmer TN, Penland C, Sakradzija M, von Storch JS, Weisheimer A, Weniger M, Williams PD, Yano JI. Stochastic parameterization toward a new view of weather and climate models. Bull Am Meteorol Soc. 2017;98(3):565-87. https://doi.org/10.1175/BAMS-D-15-00268.1.

12. von Bertalanffy L. The theory of open systems in physics and biology. Science. 1950;111(2872):23-9. https://doi.org/10.1126/ science.111.2872.23, http://science.sciencemag.org/content/111/ 2872/23.full.pdf.

13. Blossey PN, Bretherton CS, Cheng A, Endo S, Heus T, Lock AP, van der Dussen JJ. CGILS Phase 2 LES Intercomparison of response of subtropical marine low cloud regimes to $\mathrm{CO} 2$ quadrupling and a CMIP3 composite forcing change. Journal of Advances in Modeling Earth Systems. 2016;8(4):1714-26. https://doi.org/10.1002/2016MS000765.

14. Boers N, Rheinwalt A, Bookhagen B, Barbosa HMJ, Marwan N, Marengo J, Kurths J. The South American rainfall dipole: a complex network analysis of extreme events. Geophys Res Lett. 2014;41(20):7397-405. https://doi.org/10.1002/2014GL061829.

15. Bogenschutz PA, Krueger SK. A simplified PDF parameterization of subgrid-scale clouds and turbulence for cloud-resolving models. Journal of Advances in Modeling Earth Systems. 2013;5(2):195211. https://doi.org/10.1002/jame.20018.

16. Böing S. An object-based model for convective cold pool dynamics. Mathematics of Climate and Weather Forecasting. 2016;2:43-60. https://doi.org/10.1515/mcwf-2016-0003.

17. Bollasina MA, Ming Y, Ramaswamy V. Anthropogenic aerosols and the weakening of the South Asian summer monsoon. Science. 2011;334(6055):502-5. https://doi.org/10.1126/ science. 1204994.

18. Boucher O, Randall D, Artaxo P, Bretherton C, Feingold G, Forster P, Kerminen VM, Kondo Y, Liao H, Lohmann U, Rasch P, Satheesh S, Sherwood S, Stevens B, Zhang X. In: Clouds and aerosols. Cambridge: Cambridge University Press; 2013. United Kingdom and new york, NY, USA, book section Chapter 7, pp 571-658. https://doi.org/10.1017/CBO97811074 15324.016.

19. Brenguier J, Pawlowska H, Schuller L. Cloud microphysical and radiative properties for parameterization and satellite monitoring of the indirect effect of aerosol on climate. J Geophys Res Atmos. 2003; 108(D15). https://doi.org/10.1029/2002 JD002682.

20. Bretherton CS. Insights into low-latitude cloud feedbacks from high-resolution models. Philosophical Transactions of the Royal Society A-Mathematical Physical and Engineering Sciences. 2015;373(2054):20140,415. https://doi.org/10.1098/rsta.2014.0 415.

21. Bretherton CS, Blossey PN, Uchida J. Cloud droplet sedimentation, entrainment efficiency, and subtropical stratocumulus albedo. Geophys Res Lett. 2007; 34(3). https://doi.org/10.1029/ 2006GL027648.

22. Brioude J, Cooper OR, Feingold G, Trainer M, Freitas SR, Kowal D, Ayers JK, Prins E, Minnis P, McKeen SA, Frost GJ, Hsie 
EY. Effect of biomass burning on marine stratocumulus clouds off the California coast. Atmos Chem Phys. 2009;9(22):884156. https://doi.org/10.5194/acp-9-8841-2009.

23. Carslaw KS, Lee LA, Reddington CL, Pringle KJ, Rap A, Forster PM, Mann GW, Spracklen DV, Woodhouse MT, Regayre LA, Pierce JR. Large contribution of natural aerosols to uncertainty in indirect forcing. Nature. 2013;503(7474):67-+. https://doi.org/10.1038/nature12674, Promotes the importance of understanding model uncertainty through the use of a statistical emulator to address paramateric uncertainty in $\mathrm{ERF}_{\mathrm{aci}}$ estimates. Finds that uncertainty in PI aerosol is the largest source of uncertainty.

24. Carslaw KS, Gordon H, Hamilton DS, Johnson JS, Regayre LA, Yoshioka M, Pringle KJ. Aerosols in the pre-industrial atmosphere. Current Climate Change Reports. 2017;3(1):1-15. https://doi.org/10.1007/s40641-017-0061-2.

25. Charlson R, Schwartz S, Hales J, Cess R, Coakley J, Hansen J, Hofmann D. Climate forcing by anthropogenic aerosols. Science. 1992;255(5043):423-30. https://doi.org/10.1126/science.255.50 43.423.

26. Chen YC, Christensen MW, Stephens GL, Seinfeld JH. Satellite-based estimate of global aerosol-cloud radiative forcing by marine warm clouds. Nat Geosci. 2014;7(9):6436. https://doi.org/10.1038/NGEO2214, Analysis of a very large (7.3 million samples), satellite-based data set to estimate the PD $\mathrm{ERF}_{\text {aci }}$. The forcing is broken down into extrinsic and intrinsic contributions (see "Current ERF aci $_{\text {Estimates"), each comprising }}$ about half of the forcing. Interestingly, their relative contributions of extrinsic and intrinsic forcings are similar to those from [47] based on the analysis of 50 shiptracks.

27. Christensen MW, Stephens GL. Microphysical and macrophysical responses of marine stratocumulus polluted by underlying ships: evidence of cloud deepening. J Geophys Res Atmos. 2011;116:D03,201. https://doi.org/10.1029/2010 JD014638, Through analysis of large numbers of observed shiptracks, the authors show that, under clean conditions, the addition of aerosol particles stabilizes the cloud system, increases cloud water, and deepens the clouds. The authors contrast the different responses to aerosol perturbations in closed- and open-cellular convection. In the former case, cloud brightening is primarily via a decrease in drop size while, in the latter, it is primarily a result of an increase in cloudiness. These two responses have been demonstrated by process models (e.g., [158]).

28. Christensen MW, Neubauer D, Poulsen C, Thomas G, McGarragh G, Povey AC, Proud S, Grainger RG. Unveiling aerosolcloud interactions part 1: Cloud contamination in satellite products enhances the aerosol indirect forcing estimate. Atmos Chem Phys Discuss. 2017. https://doi.org/10.5194/acp-2017-450, This study uses distance to remove cloud effects on aerosol. While there is no doubt that this reduces artifacts in ACI metrics, the distant aerosol field can also be expected to have less causal connection with the aerosol that perturbed the cloud. The resulting forcing estimate should probably be considered an upper (i.e., least negative) bound.

29. Considine G, Curry JA, Wielicki B. Modeling cloud fraction and horizontal variability in marine boundary layer clouds. J Geophys Res Atmos. 1997;102(D12):13,517-25. https://doi.org/10. 1029/97JD00261.

30. Dagan G, Koren I, Altaratz O. Competition between core and periphery-based processes in warm convective clouds - from invigoration to suppression. Atmos Chem Phys. 2015;15(5):2749-60. https://doi.org/10.5194/acp-15-2749-2015.

31. Feingold G, McComiskey A. ARM'S Aerosol-CloudPrecipitation Research (Aerosol Indirect Effects). Atmospheric radiation measurement (ARM) program: The first 20 years, Meteorological Monographs, vol 57. In: Turner DD and Ellingson RG, editors; 2016. https://doi.org/10.1175/AMSMONOGRAPHS-D15-0022.1.

32. Feingold G, McComiskey A, Yamaguchi T, Johnson JS, Carslaw KS, Schmidt KS. New approaches to quantifying aerosol influence on the cloud radiative effect. Proc Natl Acad Sci USA. 2016;113(21):5812-9. https://doi.org/10.1073/pnas. 1514035112.

33. Feingold G, Eberhard W, Veron D, Previdi M. First measurements of the Twomey indirect effect using ground-based remote sensors. Geophys Res Lett. 2003; 30(6). https://doi.org/10.10 29/2002GL016633.

34. Feingold G, Jiang H, Harrington J. On smoke suppression of clouds in Amazonia. Geophys Res Lett. 2005; 32(2). https://doi. org/10.1029/2004GL021369.

35. Feingold G, Koren I, Wang H, Xue H, Brewer WA. Precipitation-generated oscillations in open cellular cloud fields. Nature. 2010;466(7308):849-52. https://doi.org/10.1038/nature 09314.

36. Forster PM, Andrews T, Good P, Gregory JM, Jackson LS, Zelinka M. Evaluating adjusted forcing and model spread for historical and future scenarios in the CMIP5 generation of climate models. J Geophys Res Atmos. 2013;118(3):1139-50. https://doi.org/10.1002/jgrd.50174.

37. Garrett T, Zhao C, Dong X, Mace G, Hobbs P. Effects of varying aerosol regimes on low-level Arctic stratus. Geophys Res Lett. 2004; 31(17). https://doi.org/10.1029/2004GL019928.

38. Gettelman A. Putting the clouds back in aerosol-cloud interactions. Atmos Chem Phys. 2015;15(21):12,397-411. https://doi.org/10.5194/acp-15-12397-2015, Highlights the key role that liquid-phase precipitation processes play in GCM $\mathrm{ERF}_{\mathrm{aci}}$ uncertainties by controlling the strength of the model's "lifetime effect".

39. Gettelman A, Morrison H, Terai CR, Wood R. Microphysical process rates and global aerosol-cloud interactions. Atmos Chem Phys. 2013;13(19):9855-67. https://doi.org/10.5194/acp-13-9 855-2013.

40. Gettelman A, Morrison H, Santos S, Bogenschutz P, Caldwell PM. Advanced two-moment bulk microphysics for global models. part ii: global model solutions and aerosol-cloud interactions. J Clim. 2015;28(3):1288-307. https://doi.org/10.1175/JCLI-D14-00103.1, Study showing that prognostic precipitation improves the representation of warm rain in a GCM by shifting the partitioning of precipitation formation from autoconversion to accretion; this, in turn, reduces the lifetime effect by $1 / 3$.

41. Gettelman A, Lin L, Medeiros B, Olson J. Climate feedback variance and the interaction of aerosol forcing and feedbacks. J Clim. 2016;29(18):6659-75. https://doi.org/10.1175/JCLI-D16-0151.1.

42. Ghan S, Wang M, Zhang S, Ferrachat S, Gettelman A, Griesfeller J, Kipling Z, Lohmann U, Morrison H, Neubauer D, Partridge DG, Stier P, Takemura T, Wang H, Zhang $\mathrm{K}$. Challenges in constraining anthropogenic aerosol effects on cloud radiative forcing using present-day spatiotemporal variability. Proc Natl Acad Sci USA. 2016;113(21):5804-11. https://doi.org/10.1073/pnas.1514036113.

43. Ghan SJ, Smith SJ, Wang M, Zhang K, Pringle KJ, Carslaw KS, Pierce JR, Bauer SE, Adams PJ. A simple model of global aerosol indirect effects. J Geophys Res Atmos. 2013;118(12):6688-707. https://doi.org/10.1002/jgrd.50567.

44. Glassmeier F, Feingold G. Network approach to patterns in stratocumulus clouds. Proc Natl Acad Sci USA. 2017;114(40):10,57883. https://doi.org/10.1073/pnas.1706495114. 
45. Golaz JC, Salzmann M, Donner LJ, Horowitz LW, Ming Y, Zhao M. Sensitivity of the aerosol indirect effect to subgrid variability in the cloud parameterization of the GFDL atmosphere general circulation model AM3. J Clim. 2011;24(13):3145-60. https://doi.org/10.1175/2010JCLI3945.1, This study discusses the effect of model retuning that may be required after making modifications to one of the parameterizations. The retuning can introduce changes to the climate response (such as $\mathrm{ERF}_{\mathrm{aci}}$ ) that make it very difficult to interpret what part of $\mathrm{ERF}_{\text {aci }}$ change is due to the change in the parameterization and what part is due to the retuning.

46. Golaz JC, Horowitz LW, Levy HI. Cloud tuning in a coupled climate model: Impact on 20th century warming. Geophys Res Lett. 2013;40(10):2246-51. https://doi.org/10.1002/grl.50232.

47. Goren T, Rosenfeld D. Decomposing aerosol cloud radiative effects into cloud cover, liquid water path and Twomey components in marine stratocumulus. Atmos Res. 2014;138:378-93. https://doi.org/10.1016/j.atmosres.2013.12.008.

48. Grabowski WW. Towards global large eddy simulation: superparameterization revisited. J Meteorol Soc Jpn. 2016;94(4):32744. https://doi.org/10.2151/jmsj.2016-017.

49. Gryspeerdt E, Stier P, Partridge DG. Links between satelliteretrieved aerosol and precipitation. Atmos Chem Phys. 2014;14(18):9677-94. https://doi.org/10.5194/acp-14-96772014.

50. Gryspeerdt E, Stier P, Partridge DG. Satellite observations of cloud regime development: the role of aerosol processes. Atmos Chem Phys. 2014;14(3):1141-58. https://doi.org/10.5194/acp14-1141-2014.

51. Gryspeerdt E, Quaas J, Bellouin N. Constraining the aerosol influence on cloud fraction. J Geophys Res Atmos. 2016;121(7):3566-83. https://doi.org/10.1002/2015JD023744.

52. Gryspeerdt E, Quaas J, Ferrachat S, Gettelman A, Ghan S, Lohmann U, Morrison H, Neubauer D, Partridge DG, Stier $\mathrm{P}$, Takemura T, Wang H, Wang M, Zhang K. Constraining the instantaneous aerosol influence on cloud albedo. Proc Natl Acad Sci USA. 2017;114(19):4899-904. https://doi.org/10.1073/pna s. 1617765114.

53. Harte J. Toward a synthesis of the Newtonian and Darwinian worldviews. Phys Today. 2002;55(10):29-34. https://doi.org/10. 1063/1.1522164, This influential paper takes a philosophical and multidisciplinary look at the study of complex systems. It introduces the notion of Darwinian vs. Newtonian views of complex systems, urging an appropriate balance of both approaches.

54. Heiblum RH, Altaratz O, Koren I, Feingold G, Kostinski AB, Khain AP, Ovchinnikov M, Fredj E, Dagan G, Pinto L, Yaish R, Chen Q. Characterization of cumulus cloud fields using trajectories in the center of gravity versus water mass phase space: 1 . cloud tracking and phase space description. J Geophys Res Atmos. 2016;121(11):6336-55. https://doi.org/10.1002/2015JD024186.

55. Heyn I, Block K, Mülmenstädt J, Gryspeerdt E, Kuehne P, Salzmann M, Quaas J. Assessment of simulated aerosol effective radiative forcings in the terrestrial spectrum. Geophys Res Lett. 2017;44(2):1001-7. https://doi.org/10.1002/2016GL071975, An examination of the basis for the positive longwave $\mathrm{ERF}_{\text {aci }}$ used in AR5, this study illustrates the difficulty of refuting the "expert judgment" on which the AR5 ERF aci synthesis is based.

56. Hill AA, Feingold G, Jiang H. The influence of entrainment and mixing assumption on aerosol-cloud interactions in marine stratocumulus. J Atmos Sci. 2009;66(5):1450-64. https://doi.org/10.1175/2008JAS2909.1.

57. Hoose C, Kristjansson JE, Iversen T, Kirkevag A, Seland O, Gettelman A. Constraining cloud droplet number concentration in GCMs suppresses the aerosol indirect effect. Geophys Res Lett. 2009;36. https://doi.org/10.1029/2009GL038568.

58. Hourdin F, Mauritsen T, Gettelman A, Golaz JC, Balaji V, Duan Q, Folini D, Ji D, Klocke D, Qian Y, Rauser F, Rio C, Tomassini L, Watanabe M, Williamson D. The art and science of climate model tuning. Bull Am Meteorol Soc. 2017;98(3):589602. https://doi.org/10.1175/BAMS-D-15-00135.1.

59. Jeffery CA. Inhomogeneous cloud evaporation, invariance, and Damkohler number. J Geophys Res Atmos. 2007;112(D24). https://doi.org/10.1029/2007JD008789.

60. Johnson B, Shine K, Forster P. The semi-direct aerosol effect: impact of absorbing aerosols on marine stratocumulus. Q J R Meteorol Soc. 2004;130(599, B):1407-22. https://doi.org/10.1256/qj.03.61.

61. Johnson JS, Cui Z, Lee LA, Gosling JP, Blyth AM, Carslaw KS. Evaluating uncertainty in convective cloud microphysics using statistical emulation. Journal of Advances in Modeling Earth Systems. 2015;7(1):162-87. https://doi.org/10.1002/2014 MS000383.

62. Kaufman Y, Remer L, Tanre D, Li R, Kleidman R, Mattoo S, Levy R, Eck T, Holben B, Ichoku C, Martins J, Koren I. A critical examination of the residual cloud contamination and diurnal sampling effects on MODIS estimates of aerosol over ocean. IEEE Trans Geosci Remote Sens. 2005;43(12):2886-97. https://doi.org/10.1109/TGRS.2005.858430.

63. Khairoutdinov M, Kogan Y. A new cloud physics parameterization in a large-eddy simulation model of marine stratocumulus. Mon Weather Rev. 2000;128(1):229-43. https://doi.org/10.117 5/1520-0493(2000)128<0229:ANCPPI> 2.0.CO;2.

64. Kiehl JT. Twentieth century climate model response and climate sensitivity. Geophys Res Lett. 2007;34(22):L22,710. https://doi.org/10.1029/2007GL031383.

65. Klein SA, Hall A. Emergent constraints for cloud feedbacks. Current Climate Change Reports. 2015;1(4):276-87. https://doi. org/10.1007/s40641-015-0027-1.

66. Knutti R, Masson D, Gettelman A. Climate model genealogy: generation CMIP5 and how we got there. Geophys Res Lett. 2013;40(6):1194-9. https://doi.org/10.1002/grl.50256.

67. Koren I, Feingold G. Aerosol-cloud-precipitation system as a predator-prey problem. Proc Natl Acad Sci USA. 2011;108 (30):12,227-32. https://doi.org/10.1073/pnas.1101777108.

68. Koren I, Dagan G, Altaratz O. From aerosol-limited to invigoration of warm convective clouds. Science. 2014;344(6188):11436. https://doi.org/10.1126/science.1252595.

69. Koren I, Tziperman E, Feingold G. Exploring the nonlinear cloud and rain equation. Chaos. 2017;27(1):013,107. https://doi. org/10.1063/1.4973593.

70. Koren I, Kaufman Y, Remer L, Martins J. Measurement of the effect of Amazon smoke on inhibition of cloud formation. Science. 2004;303(5662):1342-5. https://doi.org/10.1126/scien ce.1089424.

71. Koren I, Martins JV, Remer LA, Afargan H. Smoke invigoration versus inhibition of clouds over the Amazon. Science. 2008;321(5891):946-9. https://doi.org/10.1126/science.115911 85.

72. Korhonen H, Carslaw KS, Forster PM, Mikkonen S, Gordon ND, Kokkola H. Aerosol climate feedback due to decadal increases in southern hemisphere wind speeds. Geophys Res Lett. 2010;37:L02,805. https://doi.org/10.1029/2009GL041 320.

73. Kretzschmar J, Salzmann M, Mülmenstädt J, Boucher O, Quaas J. Comment on "rethinking the lower bound on aerosol radiative forcing". J Clim. 2017;30(16):6579-84. https://doi.org/ 10.1175/JCLI-D-16-0668.1. 
74. Larson V, Golaz J, Cotton W. Small-scale and mesoscale variability in cloudy boundary layers: joint probability density functions. J Atmos Sci. 2002;59(24):3519-39. https://doi.org/10. 1175/1520-0469(2002)059<3519:SSAMVI>2.0.CO;2.

75. Lebo ZJ, Feingold G. On the relationship between responses in cloud water and precipitation to changes in aerosol. Atmos Chem Phys. 2014;14(21):11,817-31. https://doi.org/10.5194/acp14-11817-2014.

76. Lebsock MD, Stephens GL, Kummerow C. Multisensor satellite observations of aerosol effects on warm clouds. J Geophys Res Atmos. 2008;113(D15):D15,205. https://doi.org/10.1029/20 08JD009876.

77. Lensky IM, Rosenfeld D. The time-space exchangeability of satellite retrieved relations between cloud top temperature and particle effective radius. Atmos Chem Phys. 2006;6:2887-94. https://doi.org/10.5194/acp-6-2887-2006.

78. Lohmann U. Anthropogenic aerosol influences on mixed-phase clouds. Current Climate Change Reports. 2017;3(1):32-44. https://doi.org/10.1007/s40641-017-0059-9, Together with [79], this review presents a very thorough overview of GCM ERF estimates and uncertainties since AR5.

79. Lohmann U. Why does knowledge of past aerosol forcing matter for future climate change? J Geophys Res Atmos. 2017;122(9):5021-3. https://doi.org/10.1002/2017JD026962.

80. Lohmann U, Ferrachat S. Impact of parametric uncertainties on the present-day climate and on the anthropogenic aerosol effect. Atmos Chem Phys. 2010;10(23):11,373-83. https://doi.org/10.5194/acp-10-11373-2010.

81. Lorenz E. Deterministic nonperiodic flow. J Atmos Sci. 1963;20(2):130-141. https://doi.org/10.1175/1520-0469(1963)0 $20<0130$ :DNF $>2.0 . \mathrm{CO} ; 2$, A landmark paper that gave birth to the study of chaos. The author reduced a complex fluid dynamical modeling system to a set of three coupled ordinary differential equations to elucidate the fundamental limits to predictability of chaotic systems. Similar dynamical system modeling approaches are popular in fields like physics, biology, and chemistry, much more so than in atmospheric physics.

82. Ma PL, Rasch PJ, Wang M, Wang H, Ghan SJ, Easter RC, Gustafson WIJ, Liu X, Zhang Y, Ma HY. How does increasing horizontal resolution in a global climate model improve the simulation of aerosol-cloud interactions? Geophys Res Lett. 2015;42(12):5058-65. https://doi.org/10.1002/2015GL064 183.

83. Mace G, Benson S. Diagnosing cloud microphysical process information from remote sensing measurements-a feasibility study using aircraft data. Part I: Tropical anvils measured during TC4. J Appl Meteorol Climatol. 2017;56(3):633-49. https://doi.org/10.1175/JAMC-D-16-0083.1.

84. Malavelle FF, Haywood JM, Ones AJ, Gettelman A, Larisse LC, Bauduin S, Allan RP, Karset IHH, Kristjansson JE, Oreopoulos L, Ho NC, Lee D, Bellouin N, Boucher O, Grosvenor DP, Carslaw KSC, Dhomse S, Mann GW, Schmidt A, Coe H, Hartley ME, Dalvi M, Hill AA, Johnson BT, Johnson CE, Knight JR, O'Connor FM, Partridge DG, Stier P, Myhre G, Platnick S, Stephens GL, Takahashi $\mathrm{H}$, Thordarson T. Strong constraints on aerosol-cloud interactions from volcanic eruptions. Nature. 2017;546(7659):485-91. https://doi.org/10.1038/nature22974, The headline result of this study is that volcanic sulfate aerosol changes the droplet number significantly, while the responses of $\mathscr{L}$ and cloud fraction are not distinguishable from meteorological noise. This illustrates the problem of energy scales for observability, as we discuss in "Why Are ERF $_{\text {aci }}$ Estimates so Challenging?": aerosol effects that are not detectable in serendipitous ACI "experiments" like shiptracks or volcanoes may still exert a climatically relevant forcing globally. In our opinion, careful ensemble modeling is required to determine what limits on $\mathscr{L}$ and cloud fraction can be placed by two months of volcanic eruption data.

85. Marchand R, Ackerman T. A cloud-resolving model with an adaptive vertical grid for boundary layer clouds. J Atmos Sci. 2011;68(5):1058-74. https://doi.org/10.1175/2010JAS3638.1.

86. Masunaga H, L'Ecuyer TS. A mechanism of tropical convection inferred from observed variability in the moist static energy budget. J Atmos Sci. 2014;71(10):3747-66. https://doi.org/10. 1175/JAS-D-14-0015.1.

87. Matsui T, Masunaga H, Pielke R, Tao W. Impact of aerosols and atmospheric thermodynamics on cloud properties within the climate system. Geophys Res Lett. 2004:31(6). https://doi.org/10. 1029/2003GL019287.

88. Mauritsen T, Stevens B, Roeckner E, Crueger T, Esch M, Giorgetta M, Haak H, Jungclaus J, Klocke D, Matei D, Mikolajewicz U, Notz D, Pincus R, Schmidt H, Tomassini L. Tuning the climate of a global model. Journal of Advances in Modeling Earth Systems. 2012;4:M00A01. https://doi.org/10.1029/2012MS000154.

89. McComiskey A, Feingold G. The scale problem in quantifying aerosol indirect effects. Atmos Chem Phys. 2012;12(2):1031-49. https://doi.org/10.5194/acp-12-1031-2012.

90. McCoy DT, Bender FAM, Grosvenor DP, Mohrmann JK, Hartmann DL, Wood R, Field PR. Predicting decadal trends in cloud droplet number concentration using reanalysis and satellite data. Atmos Chem Phys Discuss. 2017. https://doi.org/10.5194/ acp-2017-811, This paper is an example of the increasing trend of using modeled aerosol fields together with observed cloud fields to avoid the complications of retrieving aerosol in the vicinity of clouds (see also [26]). In line with arguments set out in the paper, careful assessment of the veracity of the modeled aerosol fields should be performed with consistent aggregation scales.

91. McCoy DT, Bender FAM, Mohrmann JKC, Hartmann DL, Wood R, Grosvenor DP. The global aerosol-cloud first indirect effect estimated using MODIS, MERRA, and AeroCom. J Geophys Res Atmos. 2017;122(3):1779-96. https://doi.org/10. 1002/2016JD026141.

92. McCoy DT, Burrows SM, Wood R, Grosvenor DP, Elliott SM, Ma PL, Rasch PJ, Hartmann DL. Natural aerosols explain seasonal and spatial patterns of Southern Ocean cloud albedo. Science Advances. 2015;1(6). https://doi.org/10.1126/sciadv.1500157.

93. Meskhidze N, Remer LA, Platnick S, Juarez RN, Lichtenberger AM, Aiyyer AR. Exploring the differences in cloud properties observed by the Terra and Aqua MODIS Sensors. Atmos Chem Phys. 2009;9(10):3461-75. https://doi.org/10.5194/acp-9-34612009.

94. Michibata T, Takemura T. Evaluation of autoconversion schemes in a single model framework with satellite observations. J Geophys Res Atmos. 2015;120(18):9570-90. https://doi.org/ 10.1002/2015JD023818.

95. Michibata T, Suzuki K, Sato Y, Takemura T. The source of discrepancies in aerosol-cloud-precipitation interactions between GCM and A-Train retrievals. Atmos Chem Phys. 2016;16(23):15,413-24. https://doi.org/10.5194/acp-16-154132016.

96. Myhre G, Boucher O, Breon FM, Forster P, Shindell D. Declining uncertainty in transient climate response as $\mathrm{CO}_{2}$ forcing dominates future climate change. Nat Geosci. 2015;8(3): 181-5. https://doi.org/10.1038/NGEO2371.

97. Myhre G, Forster PM, Samset BH, Hodnebrog O, Sillmann J, Aalbergsjo SG, Andrews T, Boucher O, Faluvegi G, Flaeschner D, Iversen T, Kasoar M, Kharin V, Kirkevag A, Lamarque JF, 
Olivie D, Richardson TB, Shindell D, Shine KP, Stjern CW, Takemura T, Voulgarakis A, Zwiers F. PDRMIP: a precipitation driver and response model intercomparison project-protocol and preliminary results. Bull Am Meteorol Soc. 2017;98(6):1185-98. https://doi.org/10.1175/BAMS-D-16-0019.1.

98. Nazarenko L, Rind D, Tsigaridis K, Del Genio AD, Kelley M, Tausnev N. Interactive nature of climate change and aerosol forcing. J Geophys Res Atmos. 2017;122(6):3457-80. https://doi.org/10.1002/2016JD025809.

99. Neggers RAJ, Siebesma AP, Heus T. Continuous single-column model evaluation at a permanent meteorological supersite. Bull Am Meteorol Soc. 2012;93(9):1389-400. https://doi.org/10. 1175/BAMS-D-11-00162.1.

100. Nelson EL, L'Ecuyer TS, Saleeby SM, Berg W, Herbener SR, van den Heever SC. Toward an algorithm for estimating latent heat release in warm rain systems. J Atmos Ocean Technol. 2016;33(6):1309-29. https://doi.org/10.1175/JTECH-D-15-020 5.1 .

101. Neubauer D, Lohmann U, Hoose C, Frontoso MG. Impact of the representation of marine stratocumulus clouds on the anthropogenic aerosol effect. Atmos Chem Phys. 2014;14(21):11,99712,022. https://doi.org/10.5194/acp-14-11997-2014.

102. Neubauer D, Christensen MW, Poulsen C, Lohmann U. Unveiling aerosol-cloud interactions part 2: Minimizing the effects of aerosol swelling and wet scavenging in ECHAM6-HAM2 for comparison to satellite data. Atmos Chem Phys Discuss. 2017. https://doi.org/10.5194/acp-2017-449.

103. Nober F, Graf H. A new convective cloud field model based on principles of self-organisation. Atmos Chem Phys. 2005;5:274959. https://doi.org/10.5194/acp-5-2749-2005.

104. Parishani H, Pritchard MS, Bretherton CS, Wyant MC, Khairoutdinov M. Toward low-cloud-permitting cloud superparameterization with explicit boundary layer turbulence. Journal of Advances in Modeling Earth Systems. 2017;9(3):1542-71. https://doi.org/10.1002/2017MS000968.

105. Penner JE, Xu L, Wang M. Satellite methods underestimate indirect climate forcing by aerosols. Proc Natl Acad Sci USA. 2011;108(33):13,404-8. https://doi.org/10.1073/pnas.10185261 08.

106. Poehlker ML, Poehlker C, Ditas F, Klimach T, de Angelis IH, Araujo A, Brito J, Carbone S, Cheng Y, Chi X, Ditz R, Gunthe SS, Kesselmeier J, Koenemann T, Lavric JV, Martin ST, Mikhailov E, Moran-Zuloaga D, Rose D, Saturno J, Su H, Thalman R, Walter D, Wang J, Wolff S, Barbosa HMJ, Artaxo P, Andreae MO, Poeschl U. Long-term observations of cloud condensation nuclei in the amazon rain forest—part 1: aerosol size distribution, hygroscopicity, and new model parametrizations for $\mathrm{CCN}$ prediction. Atmos Chem Phys. 2016;16(24):15,709-40. https://doi.org/10.5194/acp-16-157092016.

107. Posselt R, Lohmann U. Sensitivity of the total anthropogenic aerosol effect to the treatment of rain in a global climate model. Geophys Res Lett. 2009;36:L02,805. https://doi.org/10.1029/20 08GL035796.

108. Quaas J. Approaches to observe anthropogenic aerosol-cloud interactions. Current Climate Change Reports. 2015;1(4):297304. https://doi.org/10.1007/s40641-015-0028-0.

109. Quaas J, Stevens B, Stier P, Lohmann U. Interpreting the cloud cover-aerosol optical depth relationship found in satellite data using a general circulation model. Atmos Chem Phys. 2010;10(13):6129-35. https://doi.org/10.5194/acp-10-6129-2010.

110. Quaas J, Ming Y, Menon S, Takemura T, Wang M, Penner JE, Gettelman A, Lohmann U, Bellouin N, Boucher O, Sayer AM, Thomas GE, McComiskey A, Feingold G, Hoose C, Kristjansson JE, Liu X, Balkanski Y, Donner LJ, Ginoux
PA, Stier P, Grandey B, Feichter J, Sednev I, Bauer SE, Koch D, Grainger RG, Kirkevag A, Iversen T, Seland $\mathrm{O}$, Easter R, Ghan SJ, Rasch PJ, Morrison H, Lamarque JF, Iacono MJ, Kinne S, Schulz M. Aerosol indirect effects-general circulation model intercomparison and evaluation with satellite data. Atmos Chem Phys. 2009;9(22):8697717. https://doi.org/10.5194/acp-9-8697-2009, The first use of an emergent constraint on ACI; in light of [105] and [52], the forcing estimate should be considered approximately $30 \%$ low due to the choice of AOD as aerosol proxy.

111. Randall D, Khairoutdinov M, Arakawa A, Grabowski W. Breaking the cloud parameterization deadlock. Bull Am Meteorol Soc. 2003;84(11):1547-64. https://doi.org/10.1175/BAMS84-11-1547.

112. Rotstayn LD, Plymin EL, Collier MA, Boucher O, Dufresne JL, Luo JJ, von Salzen K, Jeffrey SJ, Foujols MA, Ming Y, Horowitz LW. Declining aerosols in CMIP5 projections: effects on atmospheric temperature structure and midlatitude jets. J Clim. 2014;27(18):6960-77. https://doi.org/10.1175/JCLID-14-00258.1.

113. Rotstayn LD, Collier MA, Shindell DT, Boucher O. Why does aerosol forcing control historical global-mean surface temperature change in CMIP5 models? J Clim. 2015;28(17):6608-25. https://doi.org/10.1175/JCLI-D-14-00712.1.

114. Salzmann M, Ming Y, Golaz JC, Ginoux PA, Morrison $\mathrm{H}$, Gettelman A, Kraemer M, Donner LJ. Two-moment bulk stratiform cloud microphysics in the GFDL AM3 GCM: description, evaluation, and sensitivity tests. Atmos Chem Phys. 2010;10(16):8037-64. https://doi.org/10.5194/acp-10-8037-2010, One of the first modeling studies pointing out the asymmetry in the treatment of cloud adjustments to aerosol, where the negative adjustment through drizzle suppression is parameterized, but the positive adjustment through enhanced turbulent entrainment is not.

115. Salzmann M, Weser H, Cherian R. Robust response of Asian summer monsoon to anthropogenic aerosols in CMIP5 models. J Geophys Res Atmos. 2014;119(19):11,32137. https://doi.org/10.1002/2014JD021783.

116. Sant V, Posselt R, Lohmann U. Prognostic precipitation with three liquid water classes in the ECHAM5-HAM GCM. Atmos Chem Phys. 2015;15(15):8717-38. https://doi.org/10. 5194/acp-15-8717-2015.

117. Satoh M, Matsuno T, Tomita H, Miura H, Nasuno T, Iga S. Nonhydrostatic icosahedral atmospheric model (NICAM) for global cloud resolving simulations. J Comput Phys. 2008;227(7):3486514. https://doi.org/10.1016/j.jcp.2007.02.006.

118. Sauter K, L'Ecuyer TS. Observational evidence for the vertical redistribution and scavenging of Saharan dust by tropical cyclones. Geophys Res Lett. 2017;44(12):6421-30. https://doi. org/10.1002/2017GL074166.

119. Schmidt GA, Bader D, Donner LJ, Elsaesser GS, Golaz JC, Hannay C, Molod A, Neale RB, Saha S. Practice and philosophy of climate model tuning across six US modeling centers. Geosci Model Dev. 2017;10(9):3207-23. https://doi.org/10. 5194/gmd-10-3207-2017, A forthright description of model tuning strategies employed by various modeling centers. Of note for our discussion of using model spread as representative of uncertainty are the $\mathrm{ERF}_{\text {aritaci }}>-1.5 \mathrm{~W} \mathrm{~m}^{-2}$ "tuning targets" motivated by maintaining a positive anthropogenic forcing throughout the 20th century. While this requirement is physically plausible, it is not symmetric (there is no corresponding upper bound on the forcing), which may bias the mean $\mathrm{ERF}_{\mathrm{aci}}$ of a model ensemble.

120. Schmidt KS, Feingold G, Pilewskie P, Jiang H, Coddington $\mathrm{O}$, Wendisch M. Irradiance in polluted cumulus fields: Measured 
and modeled cloud-aerosol effects. Geophys Res Lett. 2009;36. https://doi.org/10.1029/2008GL036848.

121. Schneider T, Teixeira J, Bretherton CS, Brient F, Pressel KG, Schar C, Siebesma AP. COMMENTARY: Climate goals and computing the future of clouds. Nat Clim Chang. 2017;7(1):3-5. https://doi.org/10.1038/nclimate3190.

122. Schreier M, Mannstein H, Eyring V, Bovensmann H. Global ship track distribution and radiative forcing from 1 year of AATSR data. Geophys Res Lett. 2007;34(17). https://doi.org/10. 1029/2007GL030664.

123. Schutgens N, Tsyro S, Gryspeerdt E, Goto D, Weigum N, Schulz M, Stier P. On the spatio-temporal representativeness of observations. Atmos Chem Phys. 2017;17(16):9761-80. https://doi.org/10.5194/acp-17-9761-2017, One of a small but increasing number of papers that recognize the importance of rigorous comparison between models and observations. This work assesses biases associated with spatiotemporal differences in regularly gridded model output and irregular observational data. A key message is that these biases may be much larger than the measurement errors themselves.

124. Schutgens NAJ, Gryspeerdt E, Weigum N, Tsyro S, Goto D, Schulz M, Stier P. Will a perfect model agree with perfect observations?: the impact of spatial sampling. Atmos Chem Phys. 2016;16(10):6335-53. https://doi.org/10.5194/acp-16-6335-20 16.

125. Schutgens NAJ, Partridge DG, Stier P. The importance of temporal collocation for the evaluation of aerosol models with observations. Atmos Chem Phys. 2016;16(2):1065-79. https:// doi.org/10.5194/acp-16-1065-2016.

126. Schwartz SE, Charlson RJ, Kahn RA, Ogren JA, Rodhe $\mathrm{H}$. Why hasn't earth warmed as much as expected? J Clim. 2010;23(10):2453-64. https://doi.org/10.1175/2009JCLI3461.1.

127. Seifert A, Heus T, Pincus R, Stevens B. Large-eddy simulation of the transient and near-equilibrium behavior of precipitating shallow convection. Journal of Advances in Modeling Earth Systems. 2015;7(4):1918-37. https://doi.org/10.1002/2015MS000 489.

128. Seinfeld JH, Bretherton C, Carslaw KS, Coe H, DeMott PJ, Dunlea EJ, Feingold G, Ghan S, Guenther AB, Kahn R, Kraucunas I, Kreidenweis SM, Molina MJ, Nenes A, Penner JE, Prather KA, Ramanathan V, Ramaswamy V, Rasch PJ, Ravishankara AR, Rosenfeld D, Stephens G, Wood R. Improving our fundamental understanding of the role of aerosol-cloud interactions in the climate system. Proc Natl Acad Sci USA. 2016;113(21):5781-90. https://doi.org/10.1073/pnas.15140431 13.

129. Sena ET, McComiskey A, Feingold G. A long-term study of aerosol-cloud interactions and their radiative effect at the southern great plains using ground-based measurements. Atmos Chem Phys. 2016;16(17):11,301-18. https://doi.org/10.5194/acp16-11301-2016.

130. Sharon T, Albrecht B, Jonsson H, Minnis P, Khaiyer M, van Reken T, Seinfeld J, Flagan R. Aerosol and cloud microphysical characteristics of rifts and gradients in maritime stratocumulus clouds. J Atmos Sci. 2006;63(3):983-97. https://doi.org/10.117 5/JAS3667.1.

131. Siebesma AP, Soares PMM, Teixeira J. A combined eddydiffusivity mass-flux approach for the convective boundary layer. J Atmos Sci. 2007;64(4):1230-48. https://doi.org/10.1175/JA S3888.1.

132. Small JD, Jiang JH, Su H, Zhai C. Relationship between aerosol and cloud fraction over Australia. Geophys Res Lett. 2011;38. https://doi.org/10.1029/2011GL049404.

133. Soden BJ, Chung ES. The large-scale dynamical response of clouds to aerosol forcing. J Clim. 2017;30(21):8783-94. https://doi.org/10.1175/JCLI-D-17-0050.1.
134. Sorooshian A, Feingold G, Lebsock MD, Jiang H, Stephens GL. On the precipitation susceptibility of clouds to aerosol perturbations. Geophys Res Lett. 2009;36:L13,803. https://doi.org/10.1029/2009GL038993.

135. Sorooshian A, Wang Z, Feingold G, L'Ecuyer TS. A satellite perspective on cloud water to rain water conversion rates and relationships with environmental conditions. J Geophys Res Atmos. 2013;118(12):6643-50. https://doi.org/10.1002/jgrd. 50523.

136. Stephens GL, Haynes JM. Near global observations of the warm rain coalescence process. Geophys Res Lett. 2007;34(20). https://doi.org/10.1029/2007GL030259, Demonstration of the power of polar orbiting cloud radar data, combined with a simple model, to infer autoconversion rates. How well process rates can be constrained by data snapshots is a question highlighted by this review.

137. Stevens B. Rethinking the lower bound on aerosol radiative forcing. J Clim. 2015;28(12):4794-819. https://doi.org/10.1175/ JCLI-D-14-00656.1.

138. Stevens B, Feingold G. Untangling aerosol effects on clouds and precipitation in a buffered system. Nature. 2009;461(7264):60713. https://doi.org/10.1038/nature08281.

139. Stevens B, Sherwood SC, Bony S, Webb MJ. Prospects for narrowing bounds on earth's equilibrium climate sensitivity. Earths Future. 2016;4(11):512-22. https://doi.org/10.1002/2016EF00 0376, Proposes a Bayesian-based approach to refuting hypotheses associated with $\mathrm{ERF}_{\mathrm{aci}}$, a much more rigorous method than the "expert judgment" used by [18] to determine ERF.

140. Stevens B, Fiedler S, Kinne S, Peters K, Rast S, Muesse J, Smith SJ, Mauritsen T. MACv2-SP: a parameterization of anthropogenic aerosol optical properties and an associated Twomey effect for use in CMIP6. Geosci Model Dev. 2017;10(1):433-52. https://doi.org/10.5194/gmd-10-433-2017.

141. Suzuki K, Stephens GL, Lebsock MD. Aerosol effect on the warm rain formation process: satellite observations and modeling. J Geophys Res Atmos. 2013;118(1):170-84. https://doi.org/10.1002/jgrd.50043.

142. Suzuki K, Stephens G, Bodas-Salcedo A, Wang M, Golaz JC, Yokohata T, Koshiro T. Evaluation of the warm rain formation process in global models with satellite observations. J Atmos Sci. 2015;72(10):3996-4014. https://doi.org/10.1175/JAS-D-14-0265.1, Contains a very useful derivation of the sensitivity of $Z-\tau_{c}$ diagrams to parameters of GCM precipitation schemes.

143. Suzuki K, Nakajima TY, Stephens GL. Particle growth and drop collection efficiency of warm clouds as inferred from Joint CloudSat and MODIS Observations. J Atmos Sci. 2010;67(9):3019-32. https://doi.org/10.1175/2010JAS3463.1, Presents a novel two-dimensional PDF of $Z$ and $\tau_{c}$ as a means of interpreting model performance against observations. With $Z$ highly sensitive to large drops and $\tau_{c}$ much more sensitive to small drops, the analysis lends insight into the balance of microphysical processes most active in the cloud. Similar in spirit to [10], but focused on microphysics.

144. Twomey S. Influence of pollution on shortwave albedo of clouds. J Atmos Sci. 1977;34(7):1149-52. https://doi.org/10.1175/152 0-0469(1977)034<1149:TIOPOT>2.0.CO; 2 .

145. Voigt A, Pincus R, Stevens B, Bony S, Boucher O, Bellouin $\mathrm{N}$, Lewinschal A, Medeiros B, Wang Z, Zhang H. Fast and slow shifts of the zonal-mean intertropical convergence zone in response to an idealized anthropogenic aerosol. Journal of Advances in Modeling Earth Systems. 2017;9(2):870-92. https://doi.org/10.1002/2016MS000902.

146. Wacker U. Competition of precipitation particles in a model with parameterized cloud microphysics. J Atmos Sci. 
1995;52(14):2577-89. https://doi.org/10.1175/1520-0469(199 5)052<2577:COPPIA $>2.0 . \mathrm{CO} ; 2$.

147. Wacker U. Nonlinear effects in a conceptual multilayer cloud model. Nonlinear Process Geophys. 2006;13(1):99-107. https://doi.org/10.5194/npg-13-99-2006.

148. Wang M, Ghan S, Liu X, L'Ecuyer TS, Zhang K, Morrison $\mathrm{H}$, Ovchinnikov M, Easter R, Marchand R, Chand D, Qian Y, Penner JE. Constraining cloud lifetime effects of aerosols using A-Train satellite observations. Geophys Res Lett. 2012;39:L15,709. https://doi.org/10.1029/2012GL052204.

149. Wang S, Wang Q, Feingold G. Turbulence, condensation, and liquid water transport in numerically simulated nonprecipitating stratocumulus clouds. J Atmos Sci. 2003;60(2):262-78. https:// doi.org/10.1175/1520-0469(2003)060<0262:TCALWT>2.0.CO;2.

150. Wang Y, Zhang R, Saravanan R. Asian pollution climatically modulates mid-latitude cyclones following hierarchical modelling and observational analysis. Nat Commun. 2014;5:3098. https://doi.org/10.1038/ncomms4098.

151. Wang Y, Jiang JH, Su H. Atmospheric responses to the redistribution of anthropogenic aerosols. J Geophys Res Atmos. 2015;120(18):9625-41. https://doi.org/10.1002/2015JD023665.

152. West REL, Stier P, Jones A, Johnson CE, Mann GW, Bellouin N, Partridge DG, Kipling Z. The importance of vertical velocity variability for estimates of the indirect aerosol effects. Atmos Chem Phys. 2014;14(12):6369-93. https://doi.org/10.5194/ac p-14-6369-2014.

153. Wielicki B, Wong T, Loeb N, Minnis P, Priestley K, Kandel R. Changes in Earth's albedo measured by satellite. Science. 2005;308(5723):825. https://doi.org/10.1126/science.1106484.

154. Wilcox EM. Stratocumulus cloud thickening beneath layers of absorbing smoke aerosol. Atmos Chem Phys. 2010;10(23):11,76977. https://doi.org/10.5194/acp-10-11769-2010.

155. Wood R. Drizzle in stratiform boundary layer clouds. Part II: Microphysical aspects. J Atmos Sci. 2005;62(9):3034-50. https://doi.org/10.1175/JAS3530.1.
156. Wood R, Kubar TL, Hartmann DL. Understanding the importance of microphysics and macrophysics for warm rain in marine low clouds. Part II: Heuristic models of rain formation. J Atmos Sci. 2009;66(10):2973-90. https://doi.org/10.1175/2009JAS3 072.1.

157. Wood R, Ackerman T, Rasch P, Wanser K. Could geoengineering research help answer one of the biggest questions in climate science? Earths Future. 2017;5(7):659-63. https://doi.org/10.1002/ 2017 EF000601.

158. Xue H, Feingold G, Stevens B. Aerosol effects on clouds, precipitation, and the organization of shallow cumulus convection. J Atmos Sci. 2008;65(2):392-406. https://doi.org/10.1175/2007J AS2428.1.

159. Yamaguchi T, Feingold G, Larson VE. Framework for improvement by vertical enhancement: a simple approach to improve representation of low and high-level clouds in largescale models. Journal of Advances in Modeling Earth Systems. 2017;9(1):627-46. https://doi.org/10.1002/2016MS000815.

160. Yuan T, Remer LA, Yu H. Microphysical, macrophysical and radiative signatures of volcanic aerosols in trade wind cumulus observed by the A-Train. Atmos Chem Phys. 2011;11(14):711932. https://doi.org/10.5194/acp-11-7119-2011.

161. Zelinka MD, Andrews T, Forster PM, Taylor KE. Quantifying components of aerosol-cloud-radiation interactions in climate models. J Geophys Res Atmos. 2014;119(12):7599615. https://doi.org/10.1002/2014JD021710.

162. Zhou C, Penner JE. Why do general circulation models overestimate the aerosol cloud lifetime effect?: a case study comparing CAM5 and a CRM. Atmos Chem Phys. 2017;17(1):21-9. https://doi.org/10.5194/acp-17-21-2017. 